\title{
Seeing the forest for more than the trees: aesthetic and contextual malleability of preferences for climate change adaptation strategies
}

\author{
Jeffrey Jenkins $^{1}$, Brett Milligan ${ }^{2}$ and Yiwei Huang ${ }^{3,4}$
}

\begin{abstract}
Climate change is still addressed largely through expert-driven processes that rely on large-scale scenarios to transmit knowledge of anticipated trends to land managers and the lay public who are forced to confront and adapt to impacts at the local level. Thus, there is a disconnect between large-scale scenarios and the top-down management paradigm that decision-makers use, and local scenarios and management actions that deal with familiar landscape features in the context of actually existing ecological disturbances and socioeconomic vulnerabilities. Downscaled visual scenarios developed through image alteration of specific landscapes are a useful way of contextualizing and communicating possible outcomes and educating participants about alternative land management strategies. Furthermore, visual imagery can allow for a greater range of information exchange than written or verbal information alone and is a particularly effective tool for conveying knowledge and gathering public opinions among communities with and without scientific backgrounds. We are therefore interested in how visual preferences for adaptive management align with participant's understandings of functional ecological resiliency and aesthetic form. To investigate this, we detail the development of a visual survey method designed to test community preferences for adaptive management of forest systems in the southern portion of California's Sierra Nevada mountain range. For each site-specific scenario, the survey assessed participant's preferences among three alternative strategies: passive management, traditional restoration practices, and practices that are adaptive to uncertainty and changing outcomes. We asked the following: Does the inclusion of explanatory text with a visual scenario affect management preference? Do preferences differ between respondent professional category? And, how does stated familiarity with place-based landscape management practices affect preferences? Our results show that inclusion of explanatory site background information and narrative text with each strategy image aided in the understanding of and buy-in for adaptive management, which is dependent on place-based context.
\end{abstract}

Key Words: adaptive management; climate change; image alteration; landscape aesthetics; scenario visualization, Sierra Nevada

\section{INTRODUCTION}

Adaptive responses to ecological degradation and climate change have often been developed through a hierarchical, expert-driven process that have involved the transmission of knowledge from scientists to decision-makers to the lay public. This approach tends to assume that design and management decisions can be made in an objective, generalizable, and purely rational way, which fails to account for the plurality of subjective, experiential, and place-specific valuation factors that are integral to and inseparable from landscapes. Expert hierarchical approaches also tend to assume that the public can readily understand, accept, and locally apply scientific findings and recommendations, and that the necessary know-how and resources to implement them are available (Shaw et al. 2009). Similarly, regional climatic scenarios can help designers and managers envision a range of evolutionary trajectories and magnitudes of future drought, wildfire, and ecological disturbances amid complex and uncertain dynamics of forest landscapes. Still, such modeled scenarios rarely anticipate future trajectories with a level of detail and specificity that resource managers need to inform decisions at a local level (Millar et al. 2007). Alternatively, the management of forests by public and private entities has the capacity to actualize more resilient outcomes across large swaths of forest, if it is able to integrate diverse, local user values, because people most directly experience the impacts of climate change and engage in behavioral change at the individual and community level (Gobster et al. 2007, Fischer 2018). Thus, there is a pressing need to downscale the scenarios of climate change research (Dockerty et al. 2005, Pettit et al. 2012, Swetnam and Korenko 2019) from abstract globally and regionally modeled scenarios to the more experiential, placespecific realities of land users.

Experiential, aesthetic preferences for landscapes are affected by a wide range of interacting factors, such as age, gender, ethnicity, recreational activities, cultural context, and situated histories (Lyons 1983, Zube et al. 1983, Kaplan and Talbot 1988, Ribe 1994, Sang et al. 2016, Dronova 2017), and many public forest management groups use aesthetics as a criterion in planning processes (Smardon 1984, Gobster and Westphal 2004). Researchers have found that there can be conflicts between aesthetic preferences and science-based ecological resiliency in forest management, particularly when it comes to practices that pose drastic departures from existing conditions. For example, timber harvesting can impact scenic beauty (Ribe 2009), and prescribed fire can be perceived to have an immediate adverse visual effect on forest stands (Anderson 1982, Taylor and Daniel 1984). Yet, ecological function, form, and aesthetic preferences can also be in alignment, as desired ecological complexity can coincide with desirable visual diversity and complexity (Dronova 2017, Filyushkina et al. 2017).

Where much of this research varies and comes into debate concerns how aesthetics is explicitly defined, if it even is, and thus approached as the basis for investigation. Our work addresses the need to specifically define aesthetics for it to be effectively applied

${ }^{1}$ Department of Management of Complex Systems, University of California, Merced, ${ }^{2}$ Landscape Architecture and Environmental Design, Department of Human Ecology, University of California, Davis, ${ }^{3}$ Department of Human Ecology, University of California, Davis, ${ }^{4}$ Department of Horticulture and Landscape Architecture, Purdue University 
in research. Specific to our research agenda, we address two critical aesthetic concerns: (1) a shift away from the privileging of the visual in favor of a more integrative model of human perception, and (2) how the relationship between aesthetics and context is actively considered and integrated into the testing of perceptual preferences for landscapes.

In both popular culture and academic studies, aesthetics is often understood as being synonymous with visual preferences or a purely visual mode of perception. Design theorist Kathryn Moore has persuasively undermined the very concept of modes of visual thinking, arguing that belief in rationalist, fragmented notions of the senses - "the presumption that the senses are discrete and function separately" - is a damaging concept — one that we have been abiding for centuries (Moore 2010, 2017). Her assertion does not downplay the visual nature of landscape. Rather, her critique is used to suggest a more integrative or holistic ontology of the visual, where visual discernment is woven into the broader mechanisms through which we think and feel, as well as being influenced by our changing values and knowledge. As Moore (2017) states, "To consider the visual in this light makes it possible to learn about why landscapes look the way they do, how and why we respond to places, and then apply this knowledge to design". This view is consistent in landscape aesthetic research that concludes that human responses to environments and visual displays can be broadly categorized as cognitive, affective, behavioral, and physiological (Sheppard 2006). Gobster et al.'s (2007) extensive literature review of landscape aesthetics research found that context - of both the features of the landscape itself and situational factors - while assumed to be a determining factor for how knowledge influences aesthetic perceptions, is often not explicitly accounted for. For these authors (all having completed many applicable cases studies), context strongly affects aesthetic experiences of landscapes and includes "effects of different landscape types" and "effects of different personal-social situational activities or concerns" (Gobster et al. 2007). The authors stress the need for more context-explicit case study research and the need to examine how knowledge affects aesthetics preferences. In defining ecological aesthetics, the authors state that humans cannot directly sense ecological quality per se, but through cultural knowledge and normative efforts, greater alignment between ecological and perceptual/aesthetic objectives is possible.

Thus, our explicit understanding of ecological and landscape aesthetics assumes that (1) they are place- and context-sensitive and entail the full range of human sensory-cognitive-affective mechanisms in their construction, (2) they are processual and mutually affective, meaning landscapes influence aesthetics and aesthetics influence landscapes (Gobster et al. 2007), and most importantly, (3) landscape aesthetics are dynamic and adaptable rather than static. It is this conception of landscape aesthetics that we test in our study.

Ecological aesthetics have been integrated into some policy and planning efforts (Dawson and Greco 1992, Gobster 1999, Ryan 2005), but whether and how aesthetic perceptions of forest resiliency are used for climate change adaptation management actions on the ground remains unclear. There is little empirical evidence about what variables may be associated with visual buy- in toward adaptation and insufficient methodological development to test such claims about the influence of aesthetics in shaping perceptions, and vice versa. Hence, we use a novel visual-textual survey to test the correlation between variables associated with participants' understanding of adaptive management for resilient forest systems - informational context, professional background, and place-based familiarity-and aesthetic preferences of alternative management scenarios and landscape features contained therein. Specifically, we ask the following: Does the inclusion of explanatory text with a visual scenario affect management preference? Do preferences differ between respondent professional categories? And, how does stated familiarity with place-based landscape management practices affect preferences? We hypothesize that the inclusion of explanatory text with image scenarios, and professional expertise and place-based familiarity (as proxies for knowledge) increase understanding of and visual buy-in for adaptive management.

This ability to ascertain preferences for and contextual understanding of adaptive management remains a key challenge for climate change resilience efforts due to a lack of clarity about what is meant by "adaptation" and "resilience" (Walker et al. 2004). These terms have different phenomenological meanings across stakeholder groups and spatial scales, and are interpreted differently in relation to how the emergent realities of accelerated climatic change are understood, such as how novel conditions are characterized amid amplified extremes and multiple potential trajectories with uncertain outcomes (Fisichelli et al. 2016). The ecological definition of resilience refers to the amount of disturbance a system can absorb without changing states; hence, early resilience strategies were described as supporting system recovery through projects that were short-term, had high amenity or commodity value, and were under ecosystem conditions that were relatively insensitive to climate change effects (Millar et al. 2007). The lexicon of resilience has evolved through socialecological systems thinking to include a full spectrum of climate change adaptation strategies used by government agencies that range from the ability to resist change to the ability to absorb change or transform systems through response and reorganization (Folke 2006, Benson and Garmestani 2011, Carpenter et al. 2014). Climate change adaptation projects vary across a continuum of adaptation strategies that appropriately vary over time, across space, and among resources, and may be disentangled for the sake of ascertaining individuated preferences and the corresponding knowledge needed to facilitate on-theground action (Fisichelli et al. 2016). In this study, we modify the terminology of three separate approaches: autonomous change (or passive self-organization), persistence strategies (or intervention through restoration), and directed change (or what is often conceived of as adaptive management). Each strategy has its limits and situational effectiveness; we re-emphasize that while we label one as adaptive management for the purposes of this study, we do so in order to assess the a priori understandings of different stakeholder groups and the degree to which land user and manager knowledge are shaped by or help to shape aesthetic preferences for different types of landscapes, individuated features contained in scenarios of alternative climate change adaptation strategies, and the very categorical definitions of the different strategies. 


\section{Visualization as a tool for engaging communities and} stakeholders in lands management

Scenario-driven landscape visualizations offer multiple advantages in bridging epistemic frameworks of science, policy, and lived experience (Bennett and Zurek 2006), and in bringing the possible consequences and responses home to people in a compelling and accessible way (Sheppard et al. 2008). Scenario development and visualizations can facilitate community engagement and assist in collaborative approaches to planning when scientific data are too complex to be understandable and when structured processes for community outreach linked to climate change planning do not sufficiently communicate possible outcomes or are not yet in place (Tress and Tress 2003, Sheppard et al. 2011, Bennett et al. 2016). For example, this is particularly evident amid the checkerboard of public-private ownership in the wildland-urban interface, where top-down decisions and individual behaviors do not often align across the landscape when it comes to biophysical drivers of risk and wildfire risk mitigation practices (Hamilton et al. 2018).

Visual imagery and representations have been shown to be effective tools for conveying information and gathering public opinions (Al Kodmany 2000, Appleton and Lovett 2003, Sheppard and Meitner 2005), especially among communities without scientific backgrounds (Lewis and Sheppard 2006). Visual imagery can allow for a broader range of information exchange than written or verbal information alone, and in forest systems is particularly effective at distilling multiscale processes of historical change when used at the meso-scale of the landscape where higher order and smaller scale climatic, ecological, and socioeconomic processes converge (Tufte 1990, Jenkins et al. 2019). And, the combination of visual media with supporting explanatory text and narratives has been shown to be particularly effective for envisioning future landscape scenarios because the narrative provides an expansive entry point into the visualizations and vice versa (Peterson et al. 2003, Nassauer and Corry 2004, Weller 2008, Shearer 2009). Furthermore, land use, planning, and forest management agencies require knowledge about people's perceptions and interpretations of different landscapes to conduct more informed and publicly acceptable forest management strategies (Karjalainen and Tyrväinen 2002). Hence, the ability to visually depict "what if" results of different environmental management actions can help reconcile management plans and the preferences of various forest users and stakeholders (Lewis and Sheppard 2006).

In the predigital era, visualization methods consisted mostly of watercolor paintings and hand-drawn sketches to communicate management strategies to community members (Benefield and Bunce 1982, O'Riordan et al. 1993). With the development of computational technologies over the last few decades, forestry professionals have increasingly used digital visualization methods to address forest management problems (McGaughey 1998, Sheppard 2012). As these technologies have evolved, the role of public participation in proposal review has increased significantly. However, the communication of the type, extent, and severity of significant environmental changes for forests has generally been accomplished using two-dimensional maps and tabular data (Orland 1994) rather than depictions of three-dimensional forest space. Although these media may accurately depict the extent of impact, they are less likely to help users observe spatial on-the- ground effects. Since people's perceptions of an environment are directly related to and formed by places they experience, the realistic, perspectival representation of the landscape can be an effective means of triggering active and critical perception of landscape change (Lewis and Sheppard 2006, Sheppard 2012). Specifically, detailed studies have concluded that photomontage (the manipulation of two-dimensional photographic imagery) has the capacity to provide greater representative detail and a more experiential and tangible landscape view for participants (Dockerty et al. 2005). Moreover, extensive use of realistic visualizations can achieve higher levels of engagement among the public and stakeholders (Sheppard et al. 2008). Thus, researchers are increasingly using ground-level imagery and representative scenarios rather than maps or distant views from above to engage communities (Dockerty et al. 2005, Lewis and Sheppard 2006, Sheppard 2012).

In the Methods section, we provide background information on climate change and adaptive management in the southern portion of California's Sierra Nevada mountain range and detail our study's methods. This is followed by Results and Discussion, where we distil participant responses to the survey and discuss how those results inform our research questions. We end by working through the implications of the research and how our methods might be used by managers and communities to increase participation in landscape and environmental planning efforts.

\section{METHODS}

\section{Climatic change planning and adaptive management in the Sierra Nevada region}

The southern portion of California's Sierra Nevada mountain range incurs a disproportionate amount of ecological disturbance from climate change when several key hydro-ecological process are considered, including lower-than-normal precipitation in more random, higher magnitude events and associated susceptibility to earlier runoff timing, as well as increases in temperature, which in tandem create a water balance deficit throughout the forest (Lutz et al. 2010, Null et al. 2010). The duration and severity of drought conditions along with higherthan-average temperatures has resulted in a shift in the climatic envelope of many species; this has led to floristic stress throughout the region, which has greatly exacerbated natural processes such as pine bark beetle-induced tree mortality, along with higher elevation treelines and encroachment of pines into meadows. Perhaps the most significant impact to forests in the Sierra Nevada has resulted from the management paradigm of wildland fire suppression, which has led to a heavy fuel load and made largeextent, high-severity fires a more normal occurrence (Crockett and Westerling 2018). In fact, from the 1930s to the 2000s, the number of large trees in the Sierra Nevada decreased by half, while the density of small trees doubled due to a combination of timber production, fire suppression management, droughtinduced stress, and high-severity fire, all of which have resulted in a less resilient forest system (Kocher 2015).

Complex landscape-scale processes that drive ecological disturbance in forest systems are also the product of socioeconomic and political drivers (Messier et al. 2015). Forest systems are shaped by market forces such as exurban population growth and property investment; legislative mandates, 
management priorities, and local ordinances; and competing notions of economic utility from grazing and timber production to more amenity-driven economics of scenery and recreation, across a patchwork of multiple use public and private lands (Jenkins 2018a, Jenkins and Brown 2019). The most recently aggregated population data available for the region show that the southern portion of the Sierra Nevada-Inyo, Fresno, Madera, Mono, and Tulare Counties - has a population of 85,789 yearround residents, a fraction of the approximate 600,000 inhabitants living throughout the Sierra Nevada range (Hickey et al. 2005). Along with a higher level of seasonal variability associated with tourism and economic dependency compared to that of urban counties throughout California, rural communities in the Sierra Nevada receive a fraction of the county-level funding for infrastructure and emergency management needed to address natural hazards, and thus are doubly exposed to both socioeconomic and natural vulnerabilities. Recent megafires and flood events throughout the Sierra Nevada demonstrate how rural communities and adjoining public lands remain vulnerable to hazards that pose risks to life and property. In response, agencies and communities across the region have begun to implement resilience programs and have developed adaptive management plans (Higgins and Duane 2008, Littell et al. 2012).

The State of California legislature recently passed S.B. 379 to incorporate adaptive planning and resiliency measures into local planning ordinances, and in light of variable snowpack and precipitation, legally designated source watersheds and their components, such as trees, as green infrastructure through A.B. 2480. The Sierra Business Council's Climate Adaptation and Mitigation Partnership and the Sierra Nevada Conservancy's Watershed Information Network work with regional partners to implement adaptive management practices, fund local conservation efforts, and facilitate knowledge exchange between communities. Federal lands management agencies have also updated their approach. Sequoia and Kings Canyon National Parks released a Climate-Smart Stewardship Strategy that recognizes the need to manage for changing environmental conditions in light of valued recreational resource opportunities. And, among other initiatives, the U.S. Forest Service has guided the process for the Dinkey Creek Collaborative Forest Landscape Restoration Project as part of a national program to develop coupled ecological and socioeconomic monitoring plans for collaborative adaptive management. The adoption of these adaptive frameworks by management agencies is essential for maintaining resilient forest systems, but if a dynamic landscape and otherwise rigid political-legal landscape are to be reconciled in practice, adaptive management strategies must be effectively communicated and locally contextualized to land users in order for them to buy into planning efforts.

\section{Study site selection and photographic image acquisition}

Sites in the southern Sierra Nevada were chosen to represent a variety of forest ecosystems, management agencies, and land uses. Fig. 1 and Table 1 show the sites that were ultimately selected for the development of the survey, referred to as CAMERA: Comparative Adaptive Management and Ecosystem Response Assessment. We selected sites that had distinctive yet common management issues throughout the southern Sierra Nevada, as well as broad applicability to forest management more generally. Once the sites were chosen, we performed detailed inquiry into current social and ecological issues by reviewing applicable peerreviewed literature, management plans, and public response letters to those plans. We also consulted land managers to gain a more place-specific understanding of management challenges. The goal of this background research was to understand the management decisions and plans, and their potential impacts on wildlife habitat, water resources, recreation, and economy as a basis for generating different potential management scenarios.

Fig. 1. Study sites in the southern Sierra Nevada.

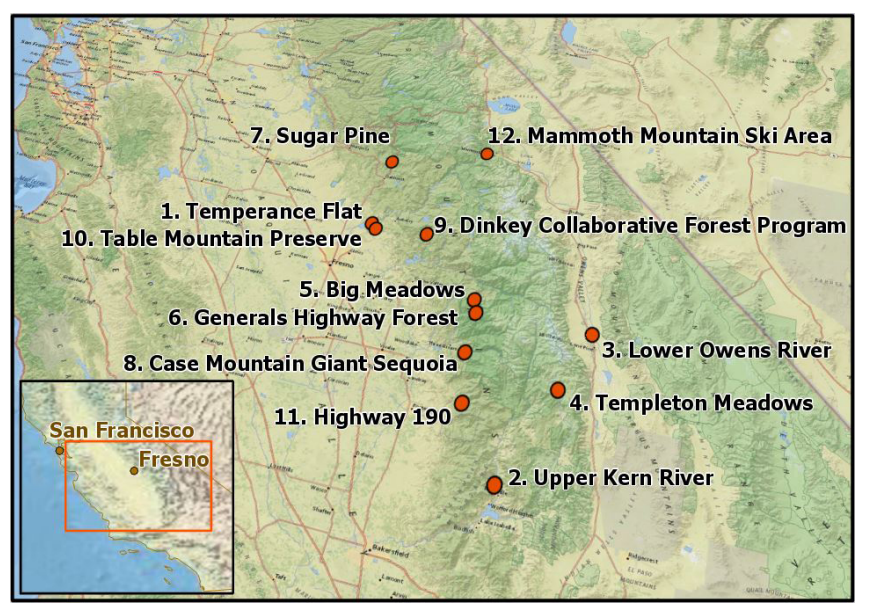

The necessary materials for producing a realistic depiction of an altered landscape include (1) a high-resolution digital photograph of the landscape in its current condition, (2) a detailed description of how the landscape is likely to evolve and change due to different management practices, and (3) a suitable stock imagery library to incorporate elements into the photo-manipulation process to represent the scenario (Dockerty et al. 2005). Thus, we visited each site and created extensive collections of digital photographic imagery to use in the visual scenarios. This included imagery of place-specific landscape elements, such as native plant species, soil types, rocks, and water features.

\section{Management strategies and visual scenarios}

For each site, we created three management strategy categories: (1) passive management, (2) restoration to an assumed functional baseline, and (3) adaptive management to future climatic uncertainty. The passive management option included management plans that take a predominantly hands-off approach by allowing landscape processes to unfold with minimal intentional human intervention. The restoration category included management plans for recovery to a previously known state or level of ecological function that was lost due to factors such as resource extraction, development, recreational uses, or the introduction of nondesirable species. The adaptive management category included strategies that actively change human and natural systems to changing environmental conditions by attempting to exploit beneficial opportunities and moderate negative effects through process-based learning and by anticipating future change. Based on these three management categories, we created three specific management trade-off scenarios for each site (Fig. 2). A necessary tension exists between 
Table 1. Study site descriptions

\begin{tabular}{|c|c|c|c|c|}
\hline Site & Name/location & Ecosystem & Vulnerabilities & Agency management \\
\hline 1 & $\begin{array}{l}\text { Temperance Flat (San Joaquin } \\
\text { River) }\end{array}$ & $\begin{array}{l}\text { River corridor, oak } \\
\text { woodland }\end{array}$ & Visitor overuse, drought & $\begin{array}{l}\text { Bureau of Reclamation, and Bureau of } \\
\text { Land Management }\end{array}$ \\
\hline 2 & Upper Kern River & River corridor & Visitor overuse, drought & Sequoia National Forest \\
\hline 3 & Lower Owens River & River corridor & Drought, overgrazing & $\begin{array}{l}\text { Los Angeles Department of Water and } \\
\text { Power }\end{array}$ \\
\hline 4 & Templeton Meadows & Meadow system & $\begin{array}{l}\text { Pine encroachment, drought, } \\
\text { overgrazing }\end{array}$ & $\begin{array}{l}\text { Golden Trout Wilderness, Inyo National } \\
\text { Forest }\end{array}$ \\
\hline 5 & Big Meadows & Meadow system & $\begin{array}{l}\text { Pine encroachment, drought, visitor } \\
\text { overuse }\end{array}$ & Sequoia National Forest \\
\hline 6 & $\begin{array}{l}\text { Generals Highway Forest } \\
\text { (Sequoia National Park) }\end{array}$ & Mixed-conifer forest & $\begin{array}{l}\text { Wildland fire, stand density, bark } \\
\text { beetle tree mortality }\end{array}$ & Sequoia National Park \\
\hline 7 & Sugar Pine (Railroad Fire) & Mixed-conifer forest & $\begin{array}{l}\text { Wildland fire, stand density, bark } \\
\text { beetle tree mortality }\end{array}$ & Sierra National Forest \\
\hline 8 & $\begin{array}{l}\text { Case Mountain Giant Sequoia } \\
\text { (Grove) }\end{array}$ & $\begin{array}{l}\text { Sequoia grove and mixed- } \\
\text { conifer forest }\end{array}$ & $\begin{array}{l}\text { Wildland fire, stand density, climatic } \\
\text { range shift }\end{array}$ & Bureau of Land Management \\
\hline 9 & $\begin{array}{l}\text { Dinkey Collaborative Forest } \\
\text { Program }\end{array}$ & Mixed-conifer forest & $\begin{array}{l}\text { Wildland fire, stand density, climatic } \\
\text { range shift }\end{array}$ & $\begin{array}{l}\text { Sierra National Forest, and community } \\
\text { management }\end{array}$ \\
\hline 10 & Table Mountain Preserve & Oak woodland & $\begin{array}{l}\text { Overgrazing, drought, climatic range } \\
\text { shift }\end{array}$ & Sierra Foothill Conservancy \\
\hline 11 & $\begin{array}{l}\text { Highway } 190 \text { (near Camp } \\
\text { Nelson) }\end{array}$ & Oak woodland & Landslide/mudslide, wildland fire & $\begin{array}{l}\text { California Department of Transportation, } \\
\text { and Giant Sequoia National Monument }\end{array}$ \\
\hline 12 & Mammoth Mountain Ski Area & Alpine forest & Lack of snowfall, visitor overuse & $\begin{array}{l}\text { Inyo National Forest, Alterra Mountain } \\
\text { Company }\end{array}$ \\
\hline
\end{tabular}

the three broad scenario types that constitute our framework and the site-specific manifestations of each category; however, this standardization was deemed imperative to arrive at a set of results that were internally comparable to the parameters of the study. Given that our goal was to develop a novel method that could be used to assess regionally specific management preferences across a range of landscape types (e.g., forest, meadows, riparian) and land use alternatives (e.g., recreation, grazing, timber), we found it necessary to differentiate some aspects of design treatments that typically co-occur in practice (e.g., forest thinning and prescribed fire), which allowed us to correlate individuated elements across groupings.

The digital photo manipulation process consisted of two general steps. The first involved the selection of locations and the preparation of scenarios. This was determined by a research team that consisted of forest management staff, a lands management professor, a forest ecologist, and a landscape architecture professor. Based on the study objectives, this team determined which sites and base images to use, what each of the three different management strategies should depict to be representative, and what should specifically appear in the images. The results of this step consisted of storyboarding the suggested alterations directly onto the imagery over multiple iterations. The second step involved the actual digital manipulation of the imagery using Adobe Photoshop software, with the aim of making the images as realistic and representative as possible.

\section{Survey interface design and sampling}

The preference survey was conducted in two stages. The first stage was a pilot study conducted in April and May 2018, during which we sent out beta surveys that asked expert participants for comments and feedback. The first round of participants were from forest management and related fields, and offered feedback on the feasibility of the scenarios, the consistency of the text and images, and the credibility of the picture manipulations.

With valuable critiques and guidance from experts, we produced a more refined, second stage survey for larger dissemination. The content was integrated into an Environmental Systems Research Institute (ESRI) StoryMap webform. The StoryMap interface allowed us to integrate interactive text, images, and maps to produce a robust data-enriched narrative for immersive engagement with participants about different forest management strategies. The CAMERA survey embedded within the StoryMap was developed through a third-party survey application, SurveyGizmo. Participants were randomly assigned to one of two different survey types: both had the 12 sites listed and were organized in the same order, but one survey version provided descriptive informational context for each scenario, whereas the other did not have any accompanying text (Fig. 3). (Appendix 1 contains the complete set of site scenario images with accompanying text). For each site, the order of the three scenario images was intentionally randomized to avoid pre-assumption from participants. After reviewing all three scenarios, participants rated the three images as " 1 " being the most preferred and " 3 " being the least preferred. Furthermore, an open-ended question followed the randomized image selection for each site: "Why did you choose your most preferred strategy?"

Potential respondents for the CAMERA survey were invited from local and federal government agencies, nonprofit environmental groups, tribes, forest user groups, and other community entities that were actively involved in Sierra Nevada forest management, with the goal of learning more about participant's knowledge of adaptive management and whether it related to visual preferences associated with resilience. Survey invitees were selected from existing professional networks, "The Sierra Nevada Grassroots 
Fig. 2. Site examples from the text-based version of the survey, including site 4 - Templeton Meadows in the Gold Trout Wilderness, and site 8 - Case Mountain Giant Sequoia Complex.

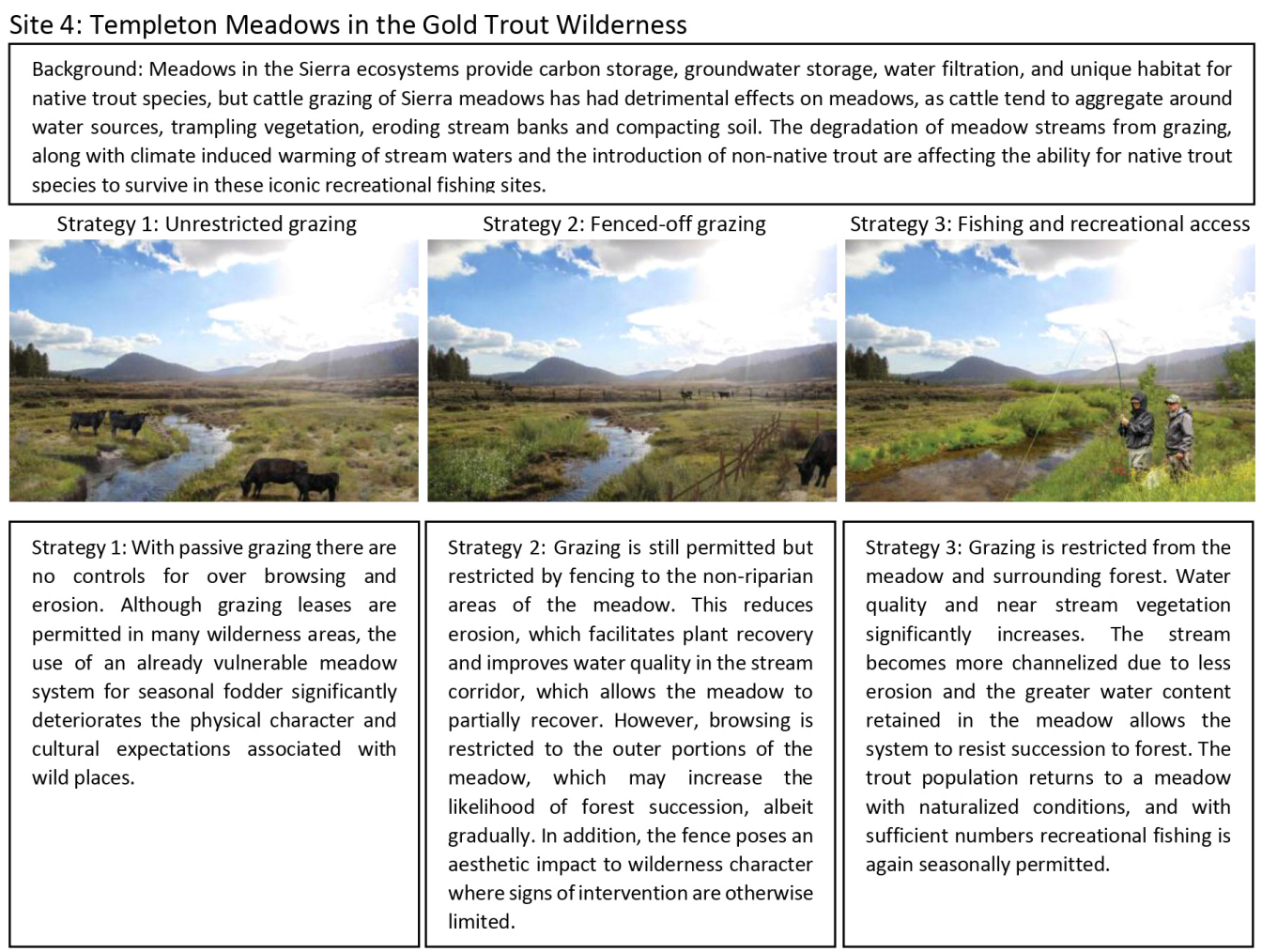

\section{Site 8: Case Mountain Giant Sequoia Complex}

Background: Climate change prediction models show that temperatures in the Southern Sierra will increase and that precipitation patterns will change inevitably affecting the narrow climatic envelope of the giant sequoia range. The groves of the Case Mountain Complex are the only giant sequoias managed by the BLM. Currently, these groves are full of dense mixed conifer growth, ladder fuel, and a heavy forest floor fuel load, all conditions that could contribute to the spread of a severe fire in the future.

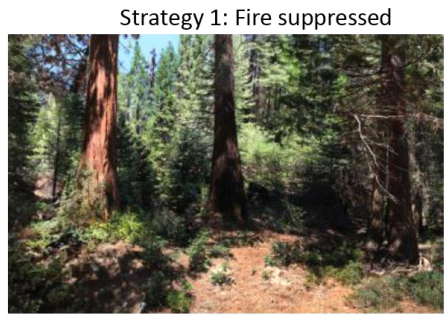

Strategy 1: Giant sequoias rely on heat from fire to open seeds in their cones. Despite this, many sequoia groves lie within forests that are otherwise managed for fire suppression. This not only limits species reproduction but also leads to overcrowding of understory vegetation and competing conifers that in turn make the groves more vulnerable to high severity fire beyond what the species has adapted to. The dense tree stands in this scenario provide limited opportunities for visitor use access, which stands in contrast to low level of groundcover of naturalized groves.
Strategy 2: Mechanically thinned

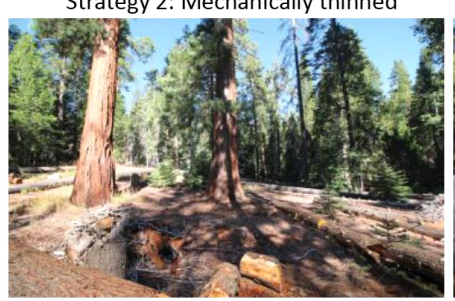

Strategy 2: One method to restore sequoia groves back to a more naturalized composition is to remove competing conifers and masticate the remaining ground cover. This mechanical thinning is a temporary solution that doesn't consider future climatic variability or maintain low level prescribed burns. Furthermore, soil compaction from mechanical thinning can poses a risk to the shallow root structure of the sequoias and this method may impact scenic expectations of visitors.
Strategy 3: Prescribed burning

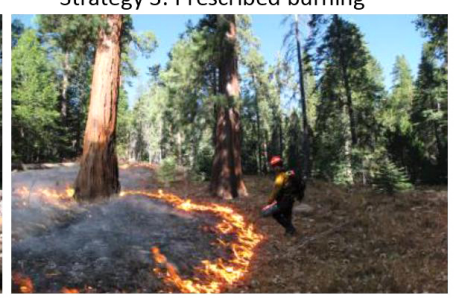

Strategy 3: The use of low-level prescribed burns in giant sequoia groves is an adaptive management strategy that allows for soil regeneration, maintenance of low groundcover, and sequoia seedlings to activate under heat. Although due to historic suppression some thinning may be necessary before low level burns can be employed, further semi-annual prescriptions can keep the groves in a functionally resilient state that's more accessible for limited visitor use. 
Fig. 3. Explanatory background and strategy content differs between the text and nontext versions of the survey. Site 6 - Generals Highway Forest shown here as one scenario example.

\section{Content for version of survey with explanatory text:}

Fig. A1.6 - Site 6: Generals Highway Forest

Background: Fire is one of the driving disturbances in forests that maintains ecological balance but because of past fire suppression, many Sierra forests have grown overcrowded and are at a higher risk for severe wildfires. Sequoia National Park was one of the first parks to employ prescribed burning as a management strategy to restore forest health and minimize the risk of severe wildfires.

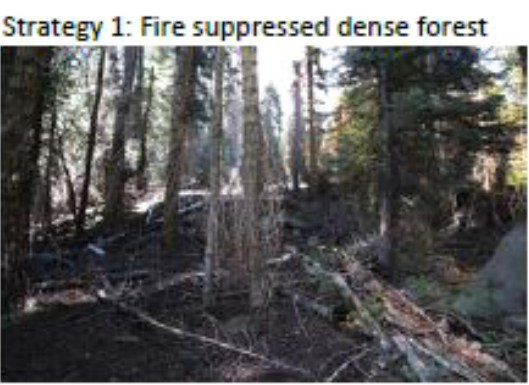

Strategy 1: Overly dense tree stands, and canopy cover impact the forest ecosystem by limiting available ground cover and light for flora, and access to habitat for many fauna. These conditions make the forest vulnerable to high severity fire and difficult to access for recreational use.
Strategy 2: Mechanically thinned forest

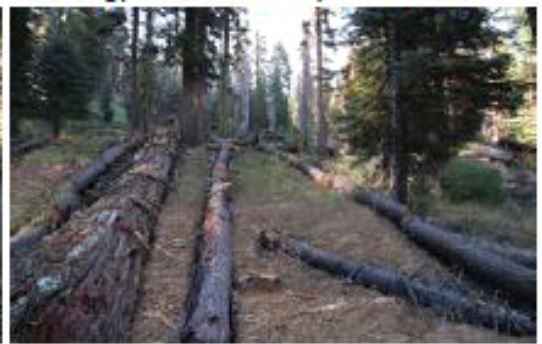

Strategy 2: Forest thinning can open canopies to provide more available light, which along with clearing of detritus on the ground can encourage more native plant growth in the understory. This improves habitat conditions for many species and reduces susceptibility to high severity fire events.
Strategy 3: Prescribed burning

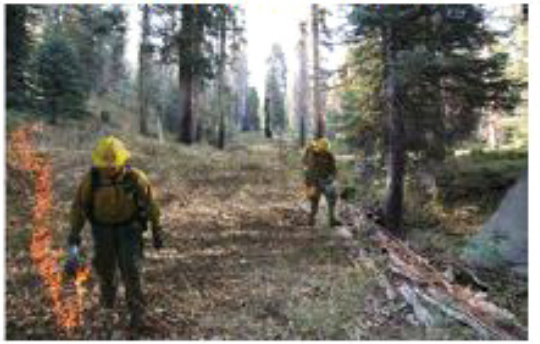

Strategy 3: Low level prescribed fire is an adaptive management method that increases forest resilience amid changing climatic conditions. Prescribed burning can maintain thinned forests, native groundcover, and increase groundwater retention. Forests managed with fire are typically more resistant to collapse like with forests that are unmanaged, overly dense, and contain less drought-tolerant endemic species.

\section{Content for version of survey without explanatory text:}

Fig. A1.6 - Site 6: Generals Highway Forest

What management strategy do you most prefer for the forests of Sequoia and Kings Canyon National Parks? Rank order the strategies from 1 to 3 , with 1 being the most preferred.
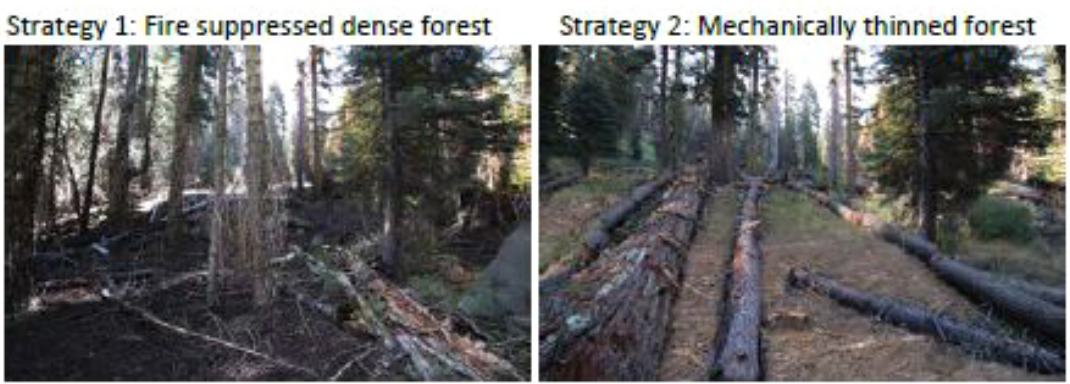

Strategy 3: Prescribed burning

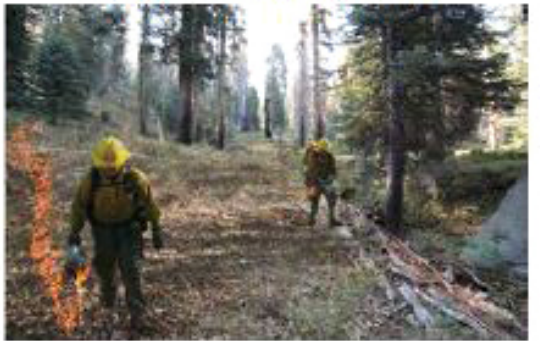


Table 2. Respondent characteristics

\begin{tabular}{|c|c|c|c|}
\hline Variable & Category & No. & $(\%)$ \\
\hline \multirow[t]{2}{*}{ Context version } & Text & 34 & $(39.0)$ \\
\hline & No text & 53 & $(61.0)$ \\
\hline \multirow[t]{3}{*}{ Gender } & Female & 40 & $(46.0)$ \\
\hline & Male & 46 & $(53.0)$ \\
\hline & Gender neutral & 1 & $(1.0)$ \\
\hline \multirow[t]{5}{*}{ Age range } & $18-25$ & 9 & $(10.0)$ \\
\hline & $26-35$ & 19 & $(22.0)$ \\
\hline & $36-45$ & 16 & $(18.5)$ \\
\hline & $46-65$ & 27 & $(31.0)$ \\
\hline & $66+$ & 16 & $(18.5)$ \\
\hline \multirow[t]{4}{*}{ Location of residence } & I live in the Sierra Nevada full-time & 41 & $(47.0)$ \\
\hline & I live near the Sierra Nevada and visit often & 20 & $(23.0)$ \\
\hline & I live in California (outside the Sierra Nevada) & 21 & $(24.0)$ \\
\hline & I live outside California & 5 & $(6.0)$ \\
\hline \multirow{7}{*}{$\begin{array}{l}\text { Profession } \\
\text { (by category) }\end{array}$} & Engineering & 8 & $(9.0)$ \\
\hline & Environmental science and policy & 28 & $(32.5)$ \\
\hline & Forestry and surveying & 6 & $(7.0)$ \\
\hline & Lands management & 8 & $(9.0)$ \\
\hline & Retired & 11 & $(12.5)$ \\
\hline & University student & 16 & $(18.5)$ \\
\hline & Other & 10 & $(11.5)$ \\
\hline \multirow[t]{3}{*}{ What is your belief about climate change? } & $\begin{array}{l}\text { It is definitely occurring; we are presently seeing the impacts and must address them } \\
\text { now }\end{array}$ & 82 & $(94.0)$ \\
\hline & $\begin{array}{l}\text { It is occurring, but the impacts are minor and we should wait to address them down } \\
\text { the line }\end{array}$ & 3 & $(3.5)$ \\
\hline & $\begin{array}{l}\text { Climate change might be happening, but it is not human caused and any possible } \\
\text { impacts are minor }\end{array}$ & 2 & $(2.5)$ \\
\hline \multirow{3}{*}{$\begin{array}{l}\text { How would you describe your familiarity with } \\
\text { lands management practices in the Sierra } \\
\text { Nevada? }\end{array}$} & Somewhat or completely unfamiliar & 14 & $(16.0)$ \\
\hline & Experiential familiarity as land user/recreationalist & 37 & $(42.5)$ \\
\hline & Expert scientist, manager, or practitioner & 36 & $(41.5)$ \\
\hline Total respondents & & 87 & \\
\hline
\end{tabular}

Directory" published by The Planning and Conservation League, and requests made to lead contacts at selected agencies and organizations. As a preliminary test for a novel methodological approach, we found this sampling strategy to be adequate. The sampling method was chosen to obtain responses from a comparable set of people who were interested in, actively working on, or otherwise experiencing the benefits of forest management practices and the aesthetic implications of functional natural design (Schroeder 1984, Pfüger et al. 2008). Based on the final set of 87 respondents, we obtained a $93.5 \%$ confidence level with a $10 \%$ margin of error for our results, which reflected a statistically relevant sample of the 85,789 residents in the five-county study area (Hickey et al. 2005). The responses we received provided a usable data set for preliminarily testing our method and providing insights for future study.

\section{RESULTS AND DISCUSSION}

We first provide an overview of respondent characteristics to situate the inference of our results. We then address each of the three research questions related to contextual significance, profession, and familiarity with place-based lands management practices. Importantly, our findings confirm that knowledge informs aesthetics preference for adaptive management, most strongly with the addition of explanatory text, with professional category and place-based familiarity serving as proxies for knowledge to arrive at the same result.

\section{Respondent characteristics}

Respondents were asked six demographic questions (Table 2). These background questions were similar to study population questions included in recent studies of forest managers' and users' knowledge, perceptions, and actions related to climate change adaptation efforts (Archie et al. 2012, Timberlake and Schultz 2017).

Gender identification was fairly even: $46(53 \%)$ males, $40(46 \%)$ females, and $1(1 \%)$ gender neutral participant. Age classes were as follows: 9 respondents $(10.0 \%)$ were $18-25$ years, $19(22.0 \%)$ were $26-35$ years, $16(18.5 \%)$ were $36-45$ years, $27(31.0 \%)$ were 46-65 years, and $16(18.5 \%)$ were 66 and older. We asked the participants about their area of residence in relation to the 12 sites: $41(47 \%)$ lived in the Sierra Nevada full-time, $20(23 \%)$ lived nearby and frequently visited the Sierra Nevada, 21 (24\%) lived in California outside the Sierra Nevada region, and $5(6 \%)$ lived outside California. Participants' job title or career choice was assigned to one of six categories: $8(9.0 \%)$ worked in an engineering field, $28(32.5 \%)$ worked in a broad range of environmental sciences and policy, $6(7.0 \%)$ worked in forestry and surveying, $8(9.0 \%)$ worked in lands management, $11(12.5 \%)$ were retired, $16(18.5 \%)$ were students, and $10(11.5 \%)$ listed their career as other. The last two questions pertained to pre-existing knowledge, belief, and experience about climate change and lands 
management. When asked about their belief in climate change, $82(94.0 \%)$ agreed that it is definitely occurring and the impacts must be addressed now, 3 (3.5\%) believed that it is occurring, but the impacts are minor and can be addressed down the line, and 2 $(2.5 \%)$ stated that climate change might be happening, but it is not human caused and possible impacts are minor. The overwhelming majority of participants who believed that climate change is happening and has real impacts confirmed the existing knowledge context of our respondents, and in this way helped validate the comparability of results. Lastly, 14 participants $(16.0 \%)$ said they are somewhat or completely unfamiliar with lands management practices in the Sierra Nevada, $37(42.5 \%)$ stated they had experiential familiarity as a land user/ recreationalist, and $36(41.5 \%)$ listed themselves as an expert scientist, manager, or practitioner.

\section{Does the inclusion of explanatory text with a photo scenario affect management preference?}

Using SurveyGizmo, survey participants were randomly divided into two groups: those who were given images with explanatory text and rationale for the management strategies (34 participants; $39 \%$ ), and those who were given no explanatory text for the images (53 participants; 61\%). Overall, the inclusion of explanatory text with scenario images clearly affected participants' choice of management scenarios. Participants who were given the text version were less likely to choose the passive strategy (3.9\% versus $9.6 \%$ for those who were not given text), and were significantly more likely to choose the adaptive management strategy $(72.5 \%$ versus $59.9 \%$ for those who were not given text) over restoration strategies $(23.4 \%$ for those given explanatory text versus $30.4 \%$ for those who were not) (Fig. 4).

Given that $94 \%$ of all survey participants stated that they believe that anthropogenic-caused climate change is happening and requires immediate, active intervention, it is not surprising that all participants displayed strong preferences for the two active management strategies across all sites, and that for those who were given explanatory text, the identification of a passive strategy became less preferred. The fact that preference for the adaptation strategies was significantly higher for those who were given explanatory text supports the hypothesis that aesthetic preferences are influenced by one's pre-existing values and the acquisition of situational knowledge (Gobster et al. 2007).

Regarding response differences across specific scenarios, a clear alignment in preference for adaptive strategies was recorded for both text and nontext version respondents at sites 1, 3, 4, 6, 7, 8, 9, 11, and 12. However, participants' open responses revealed important qualitative differences in contextual understanding of adaptive strategies between those who received the version of the survey with supporting text and those who were given the version without text. For instance, at Site 9, Dinkey Collaborative Forest, nontext participants affirmed visual cues that salvage logging can be situationally appropriate near existing fuel breaks: "Selective logging does need to occur and should be in areas that are located near WUIs [wildland-urban interfaces] and forest roadsides. Utilizing the road infrastructure as a fire break would assist in future wildfire management." Participants who received the text version maintained a more nuanced view that complimentary adaptive strategies would be needed to ensure future site-specific resilience: "Adaptive forest management that implements appropriate practices are imperative to ecosystem health. Practices will need to be site-specific and prescribed as appropriate. Some mechanical thinning to reduce the fuel biomass, followed by prescribed fire and planting of species that are believed to be successful for future conditions can all be beneficial." This last statement shows a recognition by participants that elements that are differentiated between two visual scenarios often otherwise co-occur in practice. Indeed, other survey respondents recognized that a more comprehensive adaptation strategy includes elements of restorative and adaptive practices, especially given existing perturbations of Sierra Nevada forest from fire suppression. Prescribed burning alone is just not practical for a densely forested landscape with a high fuel load, but neither would passive management be a practical option in all cases given that the potential for high-severity fire has increased in the Sierra Nevada with the advent of human settlement, especially since the 1930s when industrial timber production accelerated and a fire suppression paradigm of protecting forest commodities began to be implemented (Jenkins et al. 2019).

Ranked-order responses from the text version differed noticeably from those from the nontext version, especially at sites where more commonly accepted management strategies, such as the use of prescribed fire, were not part of the scenario. Rather, participants were more likely to choose the adaptive management scenario for novel interventionist management strategies, which suggests that the provision of additional context-specific informational led to a shift in participants' aesthetic preference, especially when less was known about the particular approach to begin with, be it altering features in a river to ensure more reliable streamflow (Site 2, Fig. 5) or assisted migration of tree species undergoing drought and heat stress due to a shifting climatic envelope (Site 10, Fig. 5).

There was a divergence in preference for restorative and adaptive strategies among respondents at Site 2, Upper Kern River. Those who received the nontext version strongly preferred the restorative strategy where river flow was channelized, instream and riverbank habitat was fully restored, and there was a notable absence of active river users. The nontext users preferred the image scenario that prioritized ecological functionality of river corridors by way of natural feature channelization and limits on recreational access. Respondents affirmed their existing knowledge of regional hydrological variability - "I'd like to see the river develop its natural floodplain again," and "variable patterns of high and low water flow is the normal state of affairs in California rivers" though it is not clear whether respondents recognized the level of human intervention that would be needed to restore natural processes or that recreational access at this popular location in summer would need to be purposely regulated. These results are supported by previous work on river flow aesthetics that has shown that when visual imagery alone is used to assess preference for rivers, intermediate or low flows and low turbidity with exposed instream and riverbank habitat are preferred in large rivers (Pflüger et al. 2010). For drought-prone and highly seasonal Mediterranean climates, such as those in California, this may relate to a pre-existing expectation that a hydrologically variable provisioning river is a "normal" healthy and scenic river. Therefore, this aesthetic preference may have to do more with what is expected than what is needed to constitute a healthy river ecosystem, let alone what is optimal for downstream provisioning to urban areas and agriculture. Those respondents who received 
Fig. 4. Percentage of responses for survey version with supporting text accompanying images versus percentage of responses for version without supporting text/nontext for each management strategy by site (with standard $10 \%$ error bar).

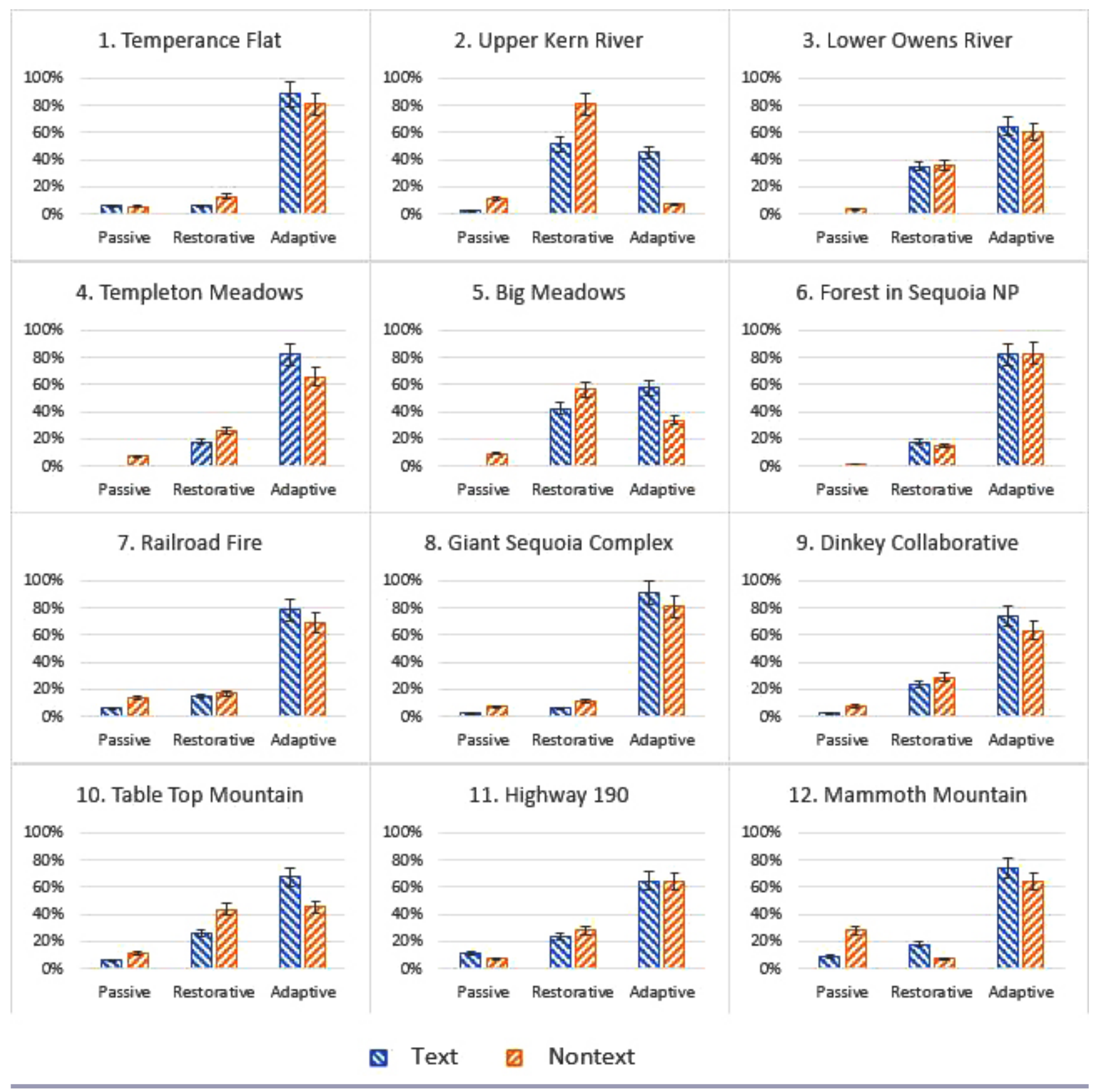

the supporting explanatory text were evenly divided in their preferences for restoration and adaptation strategies, which indicates that explanatory background context and reasoning behind each strategy led to a more informed and holistic preference. The adaptive strategy contained an altered riverbed with boulders to funnel water flow through a course that maintained rapids in low-flow years to allow for recreational use while conserving some aspects of riverbank habitat. This reflects a contextual understanding of goals that balance instream habitat with equitably distributed recreational access in a way that "works to address both ecological and economic concerns." Respondents further stated that "It strikes the best balance between human recreation and instream habitat (although I would prefer a permit/ lottery system open to the general public and not restricted to outfitters)." This again supports the hypothesis that aesthetic preferences are influenced by one's pre-existing values and the 
Fig. 5. Text versions of scenarios for site 2 - Upper Kern River, and site 10 - Table Mountain Preserve as seen in the survey. The nontext survey version did not include explanatory background and strategy content, just titles and images for each of the three strategies per site.

\section{Site 2: Upper Kern River}

Background: The Kern River is a water source for urban and agricultural use, stored in Lake Isabella, but it is also a source of tourism, linked to the local economy of the town of Kernville, in the way of camping, rafting and fishing. Climate change is predicted to cause irregularities and intensities between annual precipitation levels and snowmelt timing, thus affecting the river tourism industry that Kernville depends on

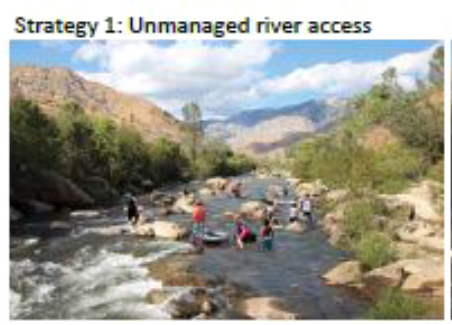

Strategy 1: A combination of low and variable precipitation years results in reduced river flow. Unmanaged impacts from high visitor use levels contribute to degraded near river habitat. The coupled impacts from continued low water levels and visitor overuse lead to a more vulnerable river ecosystem.
Strategy 2: Restored river habitat

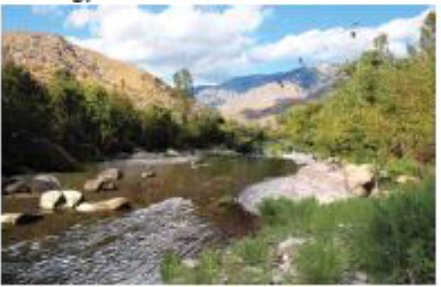

Strategy 2: The nearshore habitat of the river is restored from visitor overuse and the river is channelized to ensure a minimum water depth exists for instream species. In this case visitors are restricted from accessing the river in order to maintain restored conditions that help to buffer for climatic variability.

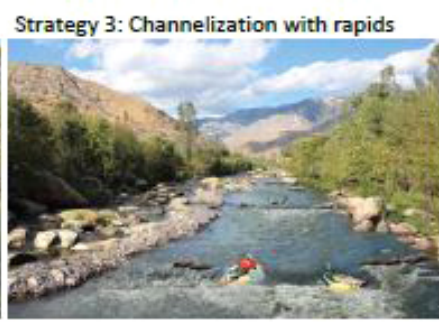

Strategy 3: This stretch of the river is managed for both habitat restoration and visitor use in variable precipitation years. River access is limited to permitted outfitters with select entry and exit points to help mitigate visitor impacts to nearshore habitat, and in river features such as rocks are engineered to create rapids for recreational use as well as instream habitat with low waterflow in mind.

\section{Site 10: Table Mountain Preserve}

Background: The Sierra foothills are a biologically diverse region of mixed oak woodlands where ranching is a historically important land use. Large ranches are significantly more beneficial to ecosystems, relative to the exurban development seen throughout the wildlandurban interface. While grazing is a culturally valued land use for some, so too are both access to recreational amenities and the ecological preservation of endemic species for others.

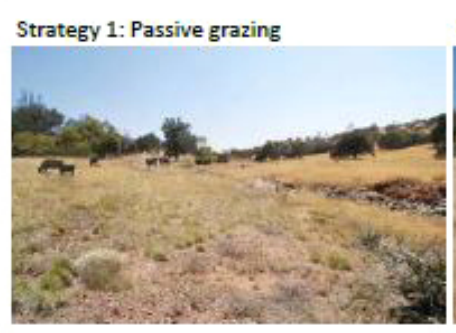

Strategy 1: Foothill ecosystems are subject to the vulnerabilities of a shifting climatic envelope and historic land uses, a double exposure that's magnified with increasingly common lower precipitation and higher temperatures years. Passive grazing is impactful if not managed, but this physical and scenic degradation is magnified when already stressed ecosystem conditions exist from drought and heat.

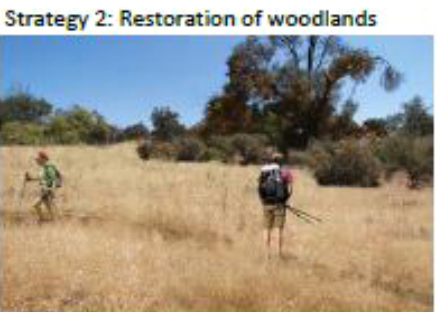

Strategy 2: Grazing can be curtailed or restricted during years of variable climatic conditions. The absence of grazing may allow vegetation to remain intact and standing, however a changing climate means that the range has shifted for plants that once flourished in this narrow temperature and precipitation band along the sierra. Despite these changing conditions, foothill open spaces will remain open for recreational use given their proximity to the valley.
Strategy 3: Assisted migration

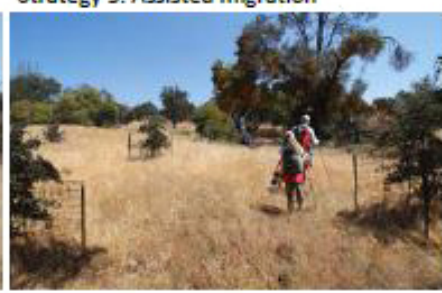

Strategy 3: An adaptive strategy for managing ecosystems with shifting climatic envelopes is to assist in the migration of species, which are themselves being pushed out of a narrow temperature and precipitation band, to a climatic-ecological niche that these species are now best suited to occupy. In this scenario continued recreational access and additional community support for assisted migration projects leads to sustained visitor use. 
acquisition of situational knowledge, particularly as it relates to weighing trade-offs and making compromises that are not as readily apparent with a purely visually informed choice (Gobster et al. 2007).

At Site 10, Table Top Mountain, respondents who received the text version of the survey were more likely to prefer the adaptive strategy than those who received the nontext version. As one respondent who received the nontext version stated about their preference for restoration, "The choice was the least objectionable. To me, restoration basically means to return to an original form or function. If an oak woodland is 'restored', then the processes remain intact for natural migration upward in elevation because the animals that effectively encourage dispersal would be present and distributing seed to the most suitable areas for growth." For them, this was the adaptive strategy, and despite a desire to confront the impacts of climatic change, the respondent lacked contextual understanding about the speed at which a tree can migrate under changing climatic conditions. This statement assumes that oak trees have a high level of vagility (i.e., ability to move themselves across the landscape) which would be needed to migrate upward in elevation due to a changing climatic envelope of temperature and precipitation, when in fact their suitable range will shift faster than the trees can be naturally assisted; thus the trees may require human assisted migration efforts, if there is public support (Jenkins and Jenkins 2017). Respondents who received the text version of the survey for Site 10 were more likely to choose adaptive management given that the associated text provided further context about the need for assisted migration and the related balance between grazing and vegetation regeneration. One respondent with the text version stated, "I don't think we should limit grazing entirely. Grazing can help reduce fire danger by keeping the vegetation down. We should experiment more with assisted species migration before we start deploying on a large scale," and another participant commented, "Cattle grazing can be compatible with restoration of the oak woodlands by using cages or herding to ensure protection of seedlings/ saplings." Still others with the text version simply commented that they learned something from the images and supporting text: "Seems like in this case intervention is good," and "never heard of assisted migration before. Let's try it!" This helped confirm our hypothesis that explanatory text affects management preference and serves as a tool for effectively communicating strategies to land users in order for them to buy into planning efforts.

And, while we attempted to make our scenarios practical, each alternative had its own assumed implementation challenges (not included in the text), such as the context of federal budget shortfalls. Fittingly, many participants used their open response to mention funding issues associated with the scenario: "will require a lot more work from the Forest Service (and a bigger budget)," and "requires money! public and private investments in our forests and watersheds." These responses highlight the potential utility of the method for managers who seek to query land users through participatory planning, particularly as it relates to surveying willingness-to-pay for certain ecological compositions of forests over others and the related fiscal practicality of prioritizing them (Nielsen et al. 2007). Of note to our argument are the varying types of implicitly or explicitly stated assumptions that respondents have, whether they are related to climatic regimes, land use activity, ecological processes, or budget woes. While we can use the inclusion or exclusion of text to assess and compare preferences and the knowledge and assumptions contained therein, other variables, including professional category, lend further inference into what type of managerial know-how leads to buy-in for certain strategies, including what is meant by the definition of a category itself.

Do preferences differ between respondent professional category? The survey results revealed similar overall preferences for management strategies by professional category and important intragroup divisions by site (Fig. 6). In this way, professional category serves as a proxy for contextual knowledge and aesthetic preference where what is "best" reflects the situated understandings of the plural and malleable definitions of adaptation itself. Most groups ranked adaptive management as the preferred strategy across the 12 survey sites: engineering $(65 \%)$, environmental science and policy $(69 \%)$, lands management $(67 \%)$, and university student $(62 \%)$. Fewer of those working in forestry and surveying preferred adaptive management $(40 \%)$ and instead chose restorative strategies $(51 \%)$ more often. No group exceeded a single-digit percentage in their preference for passive strategies. Foresters and others working in silviculture may prefer restoration strategies given the cyclical nature of timber harvests, which occur approximately every 10 20 years on average and typically require planting or seeding plots to ensure regeneration for sustained yield of timber commodities back to a reoccurring baseline of supply within parameters that make the landscape legible according to the prevailing market rationale (Brown and Daniel 1986). The typically more heterogenous and thinner compositions of stands necessary to hedge against tree mortality and high-severity fire may not comport with the more homogenous forest stands that silvicultural workers are accustomed to. And, while previous studies have demonstrated that acceptability for stand retention can differ between clumped patches and greater-extent dispersed plots, the latter being deemed more scenic, this preference is held by the general public as opposed to those working the land (Ribe 2005). The scenic aesthetics of forest landscapes are thus situated in one's mode of production; for rural livelihoods that were historically dependent on commodity production, epistemic frames of market rationality are inextricably linked to how the landscape ought to look (Nightingale 2009, Jenkins 2018b). People base their preferences on pre-existing knowledge associated with forest landscapes, and a preference for passive management may therefore be a claim to lack of contextual knowledge more than informed expertise that doing nothing is actually the best option. In fact, one participant who emphasized "letting nature take its course" in open response statements for multiple sites consistently favored restorative and adaptive strategies over passive management.

A clear preference for adaptive strategies was recorded among professional groups at sites 1, 6,8, and 11. Site 8, Case Mountain Giant Sequoia, showed the strongest convergence around the adaptive management strategies among all professional groups. This reflects the popular recognition that giant sequoia need fire for their seeds to germinate- "I recognize that the fire-adapted ecosystem of a sequoia grove must be actively managed, and I would prefer this be accomplished through a fire management strategy of regular low-intensity Rx [prescribed] fires in lieu of mechanical treatments" - and that the use of fire is a critical 
Fig. 6. Strategy responses by professional category for each site (with standard 10\% error bar).

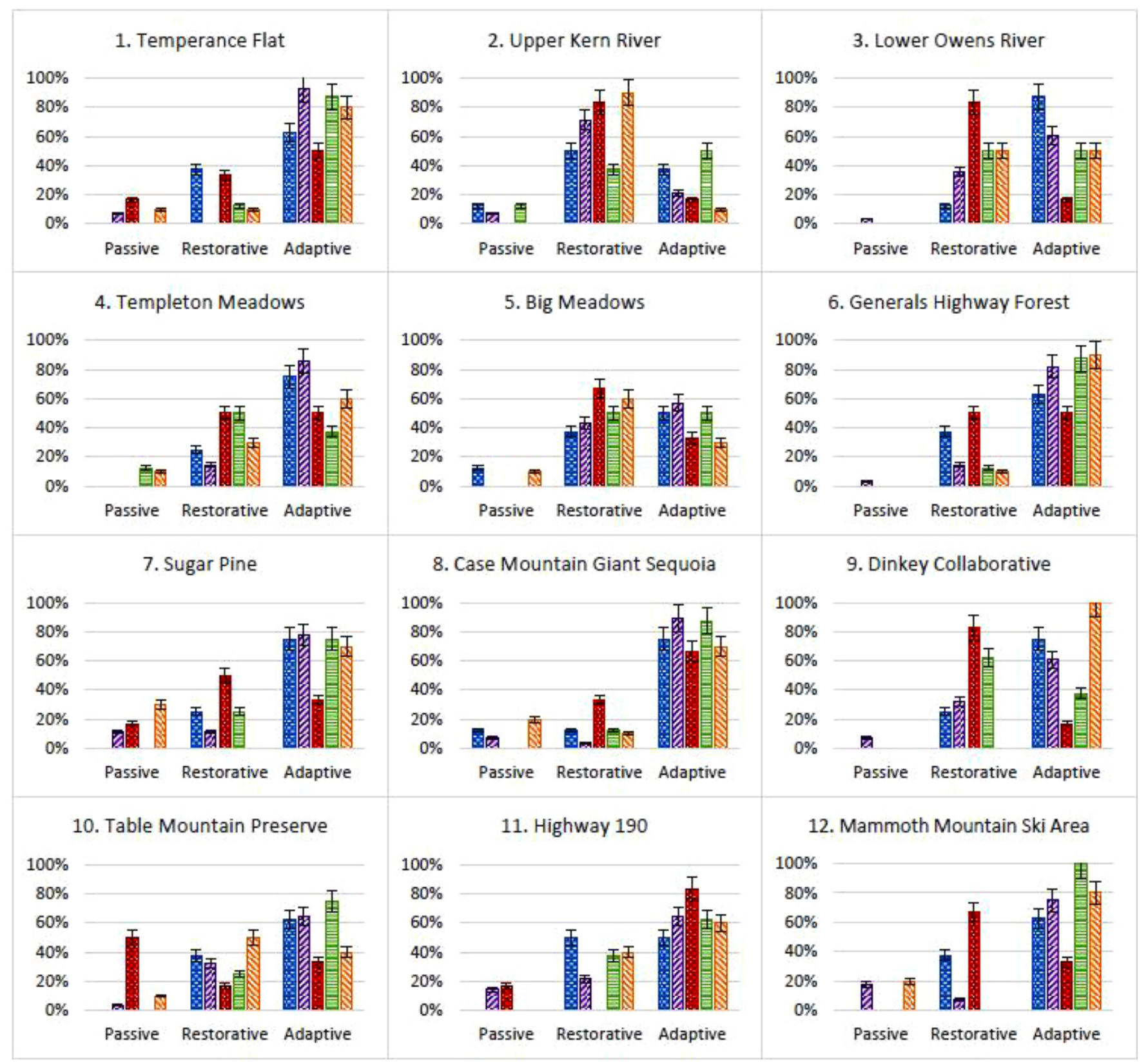

\section{田 Engineering $\mathbb{E}$ Environmental science and policy Forestry and surveying 目 Lands management $₫$ University student}

strategy in the ongoing maintenance of healthy forest systems"Reintroducing fire into these ecosystems is critical for forest health, resilience, and carbon storage under future climates." Perhaps one confounding aspect with the use of fire in sequoia groves is how to manage fire amid an otherwise dense and vulnerable understory. Sequoia grow amid mixed-conifer ecosystems that provide benefits to the grove as a whole; for instance, nutrients are sequestered in the soil, and standing deadwood and decaying trees provide critical habitat for disturbance-evolved species. But if fire has been suppressed in proximity of the grove, the dense tree stand can actually make the grove more vulnerable to catastrophic high-severity fire and leave it without the necessary ecosystem engineers. One participant commented that "The unmanaged understory vegetation in the sequoia groves has led to a grossly overly dense fire-prone condition," and another emphasized that fuel reduction should 
be focused to protect biodiversity: "Prescribed burning in giant sequoia grove indicates removal of ladder fuels focused only on small shrubs and trees, only within a burn ring immediately surrounding some sequoia trees, consistent with the protection of Pacific fisher and California Spotted Owl habitat, with no mechanical thinning throughout the grove, that is the favored and preferred strategy." Hence, open responses revealed that the very definition of adaptive management is plural and malleable, and encompasses aspects of passive, restorative, and adaptive strategy categories. While participants preferred the adaptive category overall, in actuality their stated preference for prescribed burning likely assumed that practices associated with the other individuated strategies had preceded the implementation of fire, including maintaining enough snags for ecosystem engineers, such as fisher, but also thinning understory to a presuppression era level where prescribed fire could be carried out without leading to a conflagration that would impair the grove deleteriously beyond function.

There were divergent preferences for adaptation and restoration among groups at sites 3, 4, 5, 7, 9, 10, and 12. At Site 3, Lower Owens River, respondents in the engineering profession greatly preferred the adaptive strategy with coordinated upstream water flow releases and open access to recreational fishing, whereas those in forestry and surveying preferred the restorative strategy where grazing cattle are fenced off from the river and fishing is restricted. These preferences may reflect parallels in professional mindset in terms of intervention to achieve an optimal solution and a recognition of quantifiable resource impacts, respectively. That is, much like with the aforementioned historically and economically situated preference that foresters maintain for restoration, engineers may prefer interventionist strategies due to the epistemic predisposition of empirical quantification and problem-solving that is common to their profession. Previous studies have shown that professional expertise is associated with recognition of certain elements contained in imagery and that professionals observe landscapes in patterns more similar to each other than to the lay public, though what constitutes shared expert knowledge is not necessarily defined or held in common (e.g., a landscape ecologist is a broad term encompassing many disciplines, just as an engineer can refer to expertise in different subfields) (Dupont et al. 2015). The commonality, however, is in the approach, and this may transcend into shared recognition of patterns and processes "when reading the landscape" that is to some degree regardless of the subarea of expertise. Future studies should therefore obtain more specific demographic data to disentangle specific pre-existing types of knowledge frames, but suffice it to say interpretation of definitions remains malleable and pluralistic. Relatedly, significant intragroup divisions between restoration and adaptation existed among the environmental science and policy, lands management, and university student groups. For instance, comments from those in environmental science and policy indicated that some in that group support working lands under specific circumstances: "I'd prefer allowing flash grazing by cattle when deemed appropriate," and "grazing is an important economy for the community but lacks the adaptive framework necessary to address climate change." However, those who preferred the adaptive strategy were not in favor of grazing, and instead supported practices, such as seasonal water release, that together can achieve multiple benefits; those respondents stated that "efforts to maintain a healthy yearround flow regime and restrict grazing access to mitigate potential water quality impacts seems to be an excellent strategy," and "Regulating flows in the Owens River valley may maximize water use efficiency and habitat during fluctuating precip years." Still others were prompted by the trade-offs in the images to put forth compromise solutions between grazing, habitat, and water availability with economic livelihoods in mind: "Fenced-off grazing provides some protection to vulnerable riparian areas in the arid west where there is added pressure due to limited rainfall and forage abundance. Allowing grazing in the uplands helps to maintain rural lifestyles." These open responses helped substantiate the rank-order results and findings associated with other sites that practices associated with multiple strategies are preferred, and that as a consequence, the malleability and plurality of how adaptation is interpreted and defined is highly contingent upon contextual understanding. As with profession, knowledge is similarly situated in familiarity with place-based landscape management practices.

\section{How does stated familiarity with place-based landscape management practices affect preferences?}

The survey results revealed cumulative similarities in preferred management strategy by category of self-identified familiarity with place-based management practices in the Sierra Nevada as well as differences in preferences for the three alternative strategies by site (Fig. 7). All groups chose adaptive management more often than restorative, and restorative more often than passive strategies overall: experiential familiarity as land user or recreationalist $(65 \%, 28 \%, 7 \%)$, expert scientist, manager, or practitioner $(64 \%$, $29 \%, 7 \%)$, and somewhat or completely unfamiliar $(57 \%, 33 \%$, $11 \%)$. This suggests that there is a correlation between overall management expertise and experiential familiarity with the landscape, and a preference for adaptive management strategies that by definition tend to be more situationally nuanced as part of a necessarily place-based approach.

A clear preference for adaptive strategies was recorded for all groups at sites 1, 4, 6, 7, 8, 9, and 12. Despite the usefulness of fences in achieving restoration objectives, respondents agreed on prohibiting their use for limiting the impacts of cattle in wilderness areas at Site 4, Templeton Meadows, which comports with management experience - "This is a designated Wilderness Area. Cattle grazing should not be allowed in this area,"-and recreational familiarity — "I also despise fences.... a friend recently cut his foot open from old barbed wire in a stream that we didn't see." This place-based familiarity with designations and features of the landscape affirms the phenomenological precept that our understanding of and connection to landscape is grounded in and constantly renewed through "somatic engagement" (Berleant 1992) or physical experience (Gerber and Hess 2017). Similarly, responses to Site 6, Generals Highway Forest, recognized the limitations of what treatments are feasible in a wilderness area, particularly with forest systems that have grown overly dense and dry under a regime of fire suppression: "Vegetation in Sequoia Natl. Park is grossly overly dense. There's not sufficient water to maintain the vegetation. It will result in massive wildfires. Aggressive thinning of existing vegetation back to historic levels (which means removing approximately half the current vegetation) is necessary to be able to introduce 'controlled underburns' to the landscape." Another respondent identified the 
Fig. 7. Self-identified familiarity with forest management practices in the Sierra Nevada (with standard 10\% error bar).

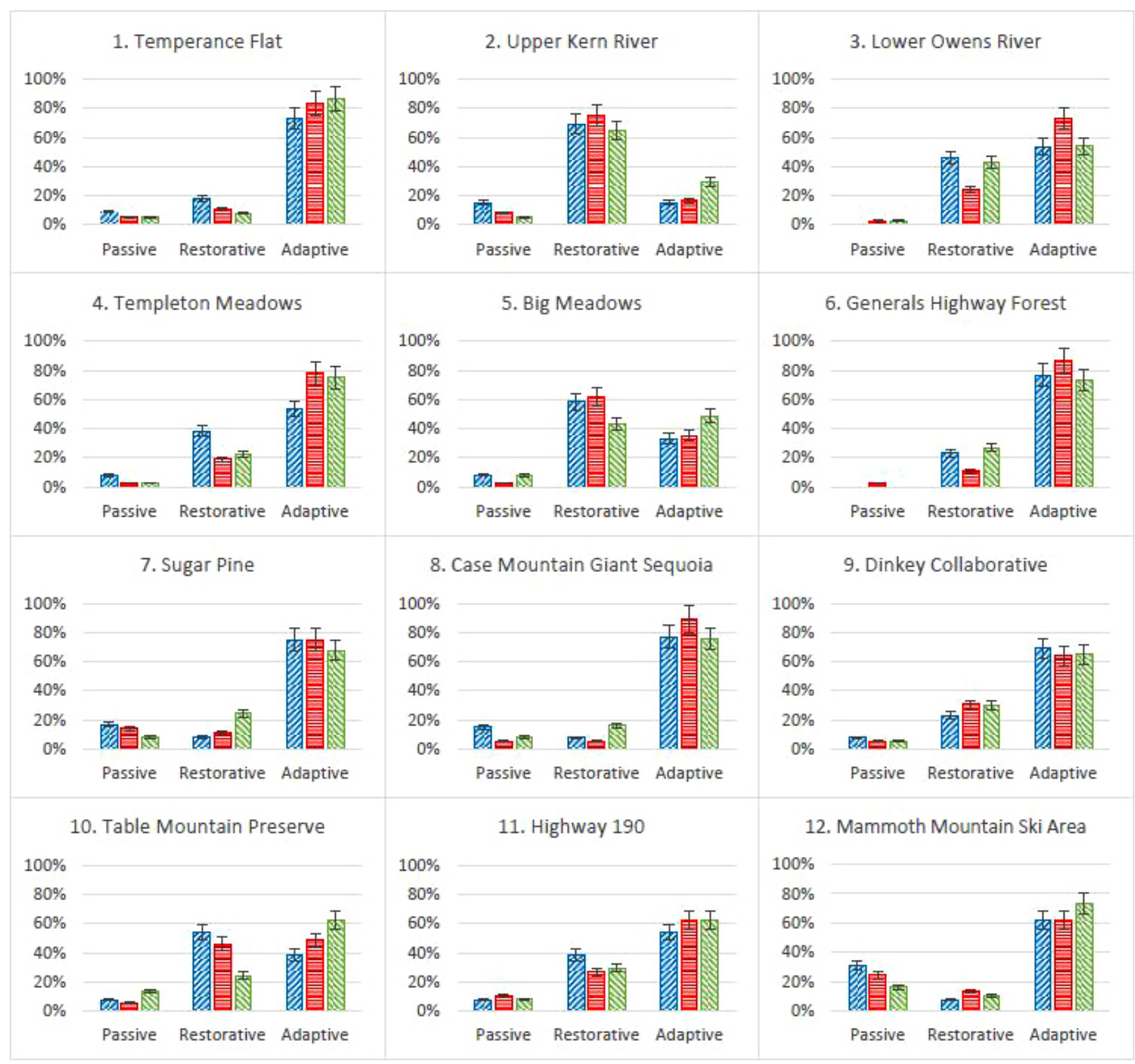

\section{Q Somewhat or completely unfamiliar \\ Experiential familiarity as land user or recreationalist $₫$ Expert scientist, manager, or practitioner}

necessary complementarity of two strategies: "You can't control a prescribed burn in most instances with this grossly overly dense condition. You need to mechanically thin it first to dramatically reduce the tree density so you then can have a successful controlled underburn to reduce surface fuel loading." Notably, these participants pushed back on the individuation of three separate approaches, instead rightfully claiming that an all-of-the-above strategy would indeed be the most resilient. This again speaks to the plurality of approaches needed for adaptation, albeit in a stepwise approach, where prescribed burning should be preceded by thinning in order to avert high-severity and out-of-control burns.

There were divided responses for adaptation and restoration among groups at sites 3, 5, 10, and 11. Responses from Site 5, Big Meadows, revealed a divide over the anticipated trajectories of 
meadow succession given climatic change, proximate impacts of trail use, and whether management interventions to stave off impacts are warranted, especially in wilderness areas. Respondents with experiential familiarity tended to favor the restorative strategy_- Meadows are too vulnerable to trampling and compaction to warrant unrestricted travel...I assume that tree 'encroachment' is a natural process - if so, it should (generally speaking) be allowed to continue," and "Let nature take its course." While cycles of conifer encroachment into and retreat from meadows is a natural process, it has been greatly accelerated in the Sierra Nevada by climatic change as temperature increases, precipitation declines, and the timing of snowpack changes that lead to early season seeding and late season drier soil conditions facilitate tree recruitment (Lubetkin et al. 2017). Expert practitioners living in the Sierra Nevada preferred planning for future climatic scenarios in order to mitigate impacts preemptively, stating that "Conifer encroachment is a big problem for many of our subalpine meadows," and "sequestration/ hydrologic/ecologic benefits may be maximized with strategy 3, which prevents meadow encroachment and, through mostly continuous sogginess, generally discourages visitor use impacts." Again, while there was divergence among groups as to what approach is most preferred, restoration versus adaptation, both are complementary and necessary. This divergence in preference for restoration versus adaptation may actually be more grounded in how laypeople versus experts interpret the temporal and spatial scale of causation: proximate impacts to meadows through recreational use happening now versus broad-scale systemic impacts wrought through climate change for the foreseeable future. This divergence, a psychological distance over the reality of nearby and near-term impacts actually happening, can in turn affect buy-in for adaptation; if climate change impacts appear to be too "near" or too threatening without a feasible solution, then people may become so overwhelmed that they feel that any response will just not be effective (Singh et al. 2017). Thus, image scenarios are an especially effective means of overcoming the cognitive trap of inevitability and disengagement, and instead operationalize individual behavior with visual buy-in of obtainable solutions.

\section{CONCLUSIONS}

Our findings infer that knowledge affects landscape aesthetic preferences. Knowledge encompasses embodied, professional, contextual, and technical domains, and in active relationship to one's aesthetic sensibilities, is dynamic and responsive to new information. In our study, this was most directly substantiated through explanatory text that provided background and context, especially for adaptive management, which is highly dependent on landscape type, both ecologically (e.g., different practices for river systems versus meadows) and by land use. Professional expertise and place-based familiarity are proxies for knowledge in that those with professional and experiential familiarity with the landscapes being assessed are more likely to align with the situational understanding of management practices. Similarly, the definitions of passive, restorative, and adaptive management are pluralistic and are understood differently among professional land managers and the lay public, likely due to situated and experiential differences in knowledge.

Future research should delve further into how knowledge about climatic disturbances and management responses are operationalized by different land user groups. In particular, recreational users represent the largest constituency of visitors to forests as land use has shifted from primarily extractive industries to a mix dominated by conservation and amenities over the last several decades (Duane 1999). Recreationalists represent a broad spectrum of the public, and the sector has grown steadily, including in the Sierra Nevada (Duane 1996), as those from more distant urban areas continue to be drawn to forests by the changing dynamics of economic ascendency and real estate markets, mobile work technologies, the sharing economy, and social media, to name a few factors. How then are the aesthetic preferences for adaptation embodied by the varying backgrounds, knowledge, and recreational activities of a changing forest user demographic? Furthermore, there remains much disparity in opportunities for recreational access to forests among the general public, and for those who are able to visit, their familiarity with landscape features and management responses are wide ranging. Future studies must be more inclusive of the entirety of the public, particularly as those living in areas outside forests and mountains rely on the provisioning of water and other ecosystem services that they may not otherwise be knowledgeable about but rely on. Communication of management strategies and the visual buy-in for adaptation gained through image scenarios is therefore most critical to achieve for those living outside the forests and mountains who do not experience those landscapes on a day-today basis, especially considering that these populations far outnumber those living in the wildland-urban interface and can have a disproportionate impact on legislation and policy.

In terms of methodology, we found that tangible, realistic, and accurate visualizations of forest management scenarios were effective in eliciting visual aesthetic preferences from survey participants. The study's outreach process and beta testing of the imagery ensured the ecological, material, and technical accuracy of what was depicted in the imagery. Outreach participants involved in this process showed strong interest in and support for the adoption of this method more widely.

Further, much design effort went into crafting the scenario imagery to make it as realistic as possible in order to minimize attention on the photographic medium itself (suspended disbelief) and focus user attention on the actual management schemes. In application, the methodology reaffirmed that use of photorealistic visualizations can achieve a high level of engagement among study participants (Sheppard et al. 2008). For researchers, the downside of this representational method was that it required specialized skills and was time-consuming, both in terms of the iterative process of getting the scenario "right" or representative according to our team of experts, and in terms of the actual work of crafting the image within software programs (Dockerty et al. 2006). However, we expect that digital image manipulation will become easier and faster as software continues to be advanced. Our study avoided using three-dimensional scenario models, such as those currently used in forestry, because they were not photographically "real" enough. But design software and photorealistic rendering programs such as Lumion, with its expanding palette of vegetation, might soon close this gap and make the iterative crafting of management scenarios much more efficient.

In summary, imagery with familiar landscape features provides a useful medium for engaging stakeholders by visually 
contextualizing information on potential outcomes. In this way, place-specific scenarios allow decision-makers to gain feedback and buy-in from land users on resilient forest management actions, thereby increasing the adaptive capacity of forestdependent communities in the Sierra Nevada and beyond.

Responses to this article can be read online at: http://www.ecologyandsociety.org/issues/responses. php/11861

\section{Acknowledgments:}

We'd like to express gratitude to CITRIS, The Center for Information Technology Research in the Interest of Society, at both University of California campuses for the seed funding opportunity that made this project possible. We'd especially like to acknowledge Zach Yinger and Dana Swarth as project research assistants for all their effort in the design of the survey interface and compilation of imagery. Special thanks also goes to Dr. Teenie Matlock and Dr. Anne Kelly for their early guidance and encouragement in the conception of this project.

\section{Data Availability:}

The data that support the findings of this study are available upon request from the corresponding author. The data are not publicly available because they could compromise the confidentially of the research participants. This study received prior approval by the Institutional Review Board (IRB) at the University of California, Merced (UCM2018-3). As such, the study was conducted in accordance with human subjects research guidelines, including ethical practices designated by the IRB.

\section{LITERATURE CITED}

Al-Kodmany, K. 2000. GIS in the urban landscape: reconfiguring neighbourhood planning and design processes. Landscape Research 25(1):5-28. https://doi.org/10.1080/014263900113145

Anderson, L. M. 1982. The esthetic effects of prescribed burning: a case study. Volume 413. U.S. Forest Service, Rocky Mountain Forest and Range Experiment Station.

Appleton, K., and A. Lovett. 2003. GIS-based visualisation of rural landscapes: defining 'sufficient' realism for environmental decision-making. Landscape and Urban Planning 65(3):117-131. https://doi.org/10.1016/S0169-2046(02)00245-1

Archie, K. M., L. Dilling, J. B. Milford, and F. C. Pampel. 2012. Climate change and western public lands: a survey of U.S. federal land managers on the status of adaptation efforts. Ecology and Society 17(4):20. https://doi.org/10.5751/ES-05187-170420

Benefield, C. B., and R. G. H. Bunce. 1982. A preliminary visual presentation of land classes in Britain. Merlewood Research and Development Paper 91.

Bennett, E. M., M. Solan, R. Biggs, T. McPhearson, A. V. Norström, P. Olsson, et al. 2016. Bright spots: seeds of a good Anthropocene. Frontiers in Ecology and the Environment 14 (8):441-448. https://doi.org/10.1002/fee.1309
Bennett, E., and M. Zurek. 2006. Integrating epistemologies through scenarios. Pages 275-294 in F. Berkes, W. V. Reid, T. Wilbanks, and D. Capistrano, editors. Bridging scales and knowledge systems: concepts and applications in ecosystem assessment. Island Press, Washington, D.C., USA.

Benson, M. H., and A. S. Garmestani. 2011. Can we manage for resilience? The integration of resilience thinking into natural resource management in the United States. Environmental Management 48(3):392-399. https://doi.org/10.1007/s00267-011-9693-5

Berleant, A. 1992. The aesthetics of environment. Temple University Press, Philadelphia, Pennsylvania, USA.

Brown, T. C., and T. C. Daniel. 1986. Predicting scenic beauty of timber stands. Forest Science 32(2):471-487.

Carpenter, S., B. Walker, J. M. Anderies, and N. Abel. 2014. From metaphor to measurement: resilience of what to what? Ecosystems 4:765-781. https://doi.org/10.1007/s10021-001-0045-9

Crockett, J. L., and A. L. Westerling. 2018. Greater temperature and precipitation extremes intensify Western U.S. droughts, wildfire severity, and Sierra Nevada tree mortality. Journal of Climate 31(1):341-354. https://doi.org/10.1175/JCLI-D-17-0254.1

Dawson, K. J., and S. E. Greco. 1992. The visual ecology of prescribed fire in Sequoia National Park. Pages 99-107 in P. S. Aune, technical coordinator. Proceedings of the Symposium on Giant Sequoias: Their Place in the Ecosystem and Society (Visalia, California, June 23-25, 1992). U.S. Forest Service General Technical Report PSW-GTR-151.

Dockerty, T., A. Lovett, K. Appleton, A. Bone, and G. Sünnenberg. 2006. Developing scenarios and visualisations to illustrate potential policy and climatic influences on future agricultural landscapes. Agriculture, Ecosystems \& Environment 114(1):103-120. https://doi.org/10.1016/j.agee.2005.11.008

Dockerty, T., A. Lovett, G. Sünnenberg, K. Appleton, and M. Parry. 2005. Visualising the potential impacts of climate change on rural landscapes. Computers, Environment and Urban Systems 29(3):297-320. https://doi.org/10.1016/j.compenvurbsys.2004.05.004

Dronova, I. 2017. Environmental heterogeneity as a bridge between ecosystem service and visual quality objectives in management, planning and design. Landscape and Urban Planning 163:90-106. https://doi.org/10.1016/j.landurbplan.2017.03.005

Duane, T. P. 1996. Recreation in the Sierra. Pages 557-610 in Sierra Nevada Ecosystem Project: final report to Congress. Volume II. Assessments and scientific basis for management options. University of California, Davis, California, USA.

Duane, T. P. 1999. Shaping the Sierra: nature, culture, and conflict in the changing West. University of California Press. https://doi. org/10.1525/9780520926141

Dupont, L., M. Antrop, and V. Van Eetvelde. 2015. Does landscape related expertise influence the visual perception of landscape photographs? Implications for participatory landscape planning and management. Landscape and Urban Planning 141:68-77. https://doi.org/10.1016/j.landurbplan.2015.05.003

Filyushkina, A., F. Agimass, T. Lundhede, N. Strange, and J. B. Jacobsen. 2017. Preferences for variation in forest characteristics: 
Does diversity between stands matter? Ecological Economics 140:22-29. https://doi.org/10.1016/j.ecolecon.2017.04.010

Fischer, A. P. 2018. Characterizing behavioral adaptation to climate change in temperate forests. Landscape and Urban Planning 188:72-79. https://doi.org/10.1016/j.landurbplan.2018.09.024

Fisichelli, N. A., G. W. Schuurman, and C. H. Hoffman. 2016. Is 'resilience' maladaptive? Towards an accurate lexicon for climate change adaptation. Environmental Management 57(4):753-758. https://doi.org/10.1007/s00267-015-0650-6

Folke, C. 2006. Resilience: the emergence of a perspective for social-ecological systems analyses. Global Environmental Change 16:253-267. https://doi.org/10.1016/j.gloenvcha.2006.04.002

Gerber, J.-D., and G. Hess. 2017. From landscape resources to landscape commons: focussing on the non-utility values of landscape. International Journal of the Commons 11(2):708-732. https://doi.org/10.18352/ijc.745

Gobster, P. H. 1999. An ecological aesthetic for forest landscape management. Landscape Journal 18(1):54-64. https://doi. org/10.3368/lj.18.1.54

Gobster, P. H., J. I. Nassauer, T. C. Daniel, and G. Fry. 2007. The shared landscape: What does aesthetics have to do with ecology? Landscape Ecology 22(7):959-972. https://doi.org/10.1007/ s10980-007-9110-X

Gobster, P. H., and L. M. Westphal. 2004. The human dimensions of urban greenways: planning for recreation and related experiences. Landscape and Urban Planning 68:147-165. https:// doi.org/10.1016/S0169-2046(03)00162-2

Hamilton, M., A. P. Fischer, S. D. Guikema, and G. Keppel-Aleks. 2018. Behavioral adaptation to climate change in wildfire-prone forests. Wiley Interdisciplinary Reviews: Climate Change 9(6): e553. https://doi.org/10.1002/wcc.553

Hickey, E., J. Clayburgh, and S. Raborn. 2005. Planning for the future: a Sierra Nevada land use index. Sierra Nevada Alliance.

Higgins, T. L., and T. P. Duane. 2008. Incorporating complex adaptive systems theory into strategic planning: The Sierra Nevada Conservancy. Journal of Environmental Planning and Management 51(1):141-162. https://doi.org/10.1080/09640560701712291

Jenkins, J. 2018a. Incommensurable or inexorable?: Comparing the economic, ecological, and social values of exchanged multiple use lands. Applied Geography 94:190-198. https://doi.org/10.1016/ j.apgeog.2018.03.018

Jenkins, J. 2018b. A 'deep' aesthetics of contested landscapes: visions of land use as competing temporalities. Geoforum 95:35-45. https://doi.org/10.1016/j.geoforum.2018.07.003

Jenkins, J., and M. Brown. 2019. Giant sequoia-forest, monument, or park?: Political-legal mandates and socioecological complexity shaping landscape-level management. Society \& Natural Resources 33:721-737. https://doi. org/10.1080/08941920.2019.1672843

Jenkins, J., A. Fleenor, and F. Dietz. 2019. Moving beyond the frame: geovisualization of landscape change along the southwestern edge of Yosemite National Park. Journal of Geovisualization and Spatial Analysis 3(2):9. https://doi. org/10.1007/s41651-019-0032-3
Jenkins, J., and M. W. Jenkins. 2017. Managed migration of coast redwoods: subjectivity of stakeholders in Oregon's land use planning community. Environment and Natural Resources Research 7(3):1. https://doi.org/10.5539/enrr.v7n3p1

Kaplan, R., and J. F. Talbot. 1988. Ethnicity and preference for natural settings: A review and recent findings. Landscape and Urban Planning 15:107-117. https://doi.org/10.1016/0169-2046 (88)90019-9

Karjalainen, E., and L. Tyrväinen. 2002. Visualization in forest landscape preference research: a Finnish perspective. Landscape and Urban Planning 59(1):13-28. https://doi.org/10.1016/ $\underline{\text { S0169-2046(01)00244-4 }}$

Kocher, S. 2015. Californians must learn from the past and work together to meet the forest and fire challenges of the next century. California Agriculture 69(1):5-9. https://doi.org/10.3733/ca. $\underline{\mathrm{v} 069 \mathrm{n} 01 \mathrm{p} 5}$

Lewis, J. L., and S. R. Sheppard. 2006. Culture and communication: Can landscape visualization improve forest management consultation with indigenous communities? Landscape and Urban Planning 77(3):291-313. https://doi. org/10.1016/j.landurbplan.2005.04.004

Littell, J. S., D. L. Peterson, C. I. Millar, and K. A. O'Halloran. 2012. U.S. National Forests adapt to climate change through science-management partnerships. Climatic Change 110 (1):269-296. https://doi.org/10.1007/s10584-011-0066-0

Lubetkin, K. C., A. L. Westerling, and L. M. Kueppers. 2017. Climate and landscape drive the pace and pattern of conifer encroachment into subalpine meadows. Ecological Applications 27(6):1876-1887. https://doi.org/10.1002/eap.1574

Lutz, J. A., J. W. van Wagtendonk, and J. F. Franklin. 2010. Climatic water deficit, tree species ranges, and climate change in Yosemite National Park. Journal of Biogeography 37(5):936-950. https://doi.org/10.1111/j.1365-2699.2009.02268.x

Lyons, E. 1983. Demographic correlates of landscape preference. Environment and Behavior 15(4):487-511. https://doi. org/10.1177/0013916583154005

McGaughey, R. J. 1998. Techniques for visualizing the appearance of forestry operations. Journal of Forestry 96(6):9-14.

Messier, C., K. Puettmann, R. Chazdon, K. P. Andersson, V. A. Angers, L. Brotons, E. Filotas, R. Tittler, L. Parrott,and S. A. Levin. 2015. From management to stewardship: viewing forests as complex adaptive systems in an uncertain world. Conservation Letters 8(5):368-377. https://doi.org/10.1111/conl.12156

Millar, C. I., N. L. Stephenson, and S. L. Stephens. 2007. Climate change and forests of the future: managing in the face of uncertainty. Ecological Applications 17(8):2145-2151. https://doi. org/10.1890/06-1715.1

Moore, K. 2010. Overlooking the visual: demystifying the art of design. Routledge.

Moore, K. 2017. Pragmatic vision: connecting aesthetics, materiality, and culture in landscape architecture practice. in I. Heywood and B. Sandywell, editors. The handbook of visual culture. Bloomsbury Publishing. 
Nassauer, J. I., and R.C. Corry. 2004. Using normative scenarios in landscape ecology. Landscape Ecology 19(4):343-356. https:// doi.org/10.1023/B:LAND.0000030666.55372.ae

Nielsen, A. B., S.B. Olsen, and T. Lundhede. 2007. An economic valuation of the recreational benefits associated with naturebased forest management practices. Landscape and Urban Planning 80(1-2):63-71. https://doi.org/10.1016/j.landurbplan.2006.06.003

Nightingale, A. 2009. Nepal's green forests; a 'thick' aesthetics of contested landscapes. Ethics, Place \& Environment 12(3):313-330. https://doi.org/10.1080/13668790903195594

Null, S. E., J. H. Viers, and J. F. Mount. 2010. Hydrologic response and watershed sensitivity to climate warming in California's Sierra Nevada. PLoS One 5(4). https://doi.org/10.1371/journal. pone.0009932

O'Riordan, T., C. Wood, and A. Shadrake. 1993. Landscapes for tomorrow. Journal of Environmental Planning and Management 36(2):123-147. https://doi.org/10.1080/09640569308711934

Orland, B. 1994. Visualization techniques for incorporation in forest planning geographic information systems. Landscape and Urban Planning 30:83-97. https://doi.org/10.1016/0169-2046(94) $\underline{90069-8}$

Peterson, G. D., G. S. Cumming, and S. R. Carpenter. 2003. Scenario planning: a tool for conservation in an uncertain world. Conservation Biology 17(2):358-366. https://doi.org/10.1046/ j.1523-1739.2003.01491.x

Pettit, C., I. Bishop, V. Sposito, J.-P. Aurambout, and F. Sheth. 2012. Developing a multi-scale visualisation framework for use in climate change response. Landscape Ecology 27(4):487-508. https://doi.org/10.1007/s10980-012-9716-5

Pflüger, Y., A. Rackham, and S. Larned. 2010. The aesthetic value of river flows: an assessment of flow preferences for large and small rivers. Landscape and Urban Planning 95:68-78. https://doi. org/10.1016/j.landurbplan.2009.12.004

Ribe, R. G. 1994. Scenic beauty perceptions along the ROS. Journal of Environmental Management 42(3):199-221. https://doi. org/10.1006/jema.1994.1069

Ribe, R. G. 2005. Aesthetic perceptions of green-tree retention harvests in vista views: the interaction of cut level, retention pattern and harvest shape. Landscape and Urban Planning 73 (4):277-293. https://doi.org/10.1016/j.landurbplan.2004.07.003

Ribe, R. G. 2009. In-stand scenic beauty of variable retention harvests and mature forests in the U.S. Pacific Northwest: the effects of basal area, density, retention pattern and down wood. Journal of Environmental Management 91(1):245-260. https://doi. org/10.1016/j.jenvman.2009.08.014

Ryan, R. L. 2005. Social science to improve fuels management: a synthesis of research on aesthetics and fuels management. General Technical Report NC-261, US Forest Service, St. Paul, Minnesota, USA. https://doi.org/10.2737/NC-GTR-261

Sang, Å. O., I. Knez, B. Gunnarsson, and M. Hedblom. 2016. The effects of naturalness, gender, and age on how urban green space is perceived and used. Urban Forestry \& Urban Greening 18:268-276. https://doi.org/10.1016/j.ufug.2016.06.008
Schroeder, H. W. 1984. Environmental perception rating scales: a case for simple methods of analysis. Environment and Behavior 16(5):573-598. https://doi.org/10.1177/0013916584165003

Shaw, A., S. Sheppard, S. Burch, D. Flanders, A. Wiek, J. Carmichael, J. Robinson, and S. Cohen. 2009. Making local futures tangible - synthesizing, downscaling, and visualizing climate change scenarios for participatory capacity building. Global Environmental Change 19(4):447-463. https://doi. org/10.1016/j.gloenvcha.2009.04.002

Shearer, A. W. 2009. Scenario-based studies for landscape planning. Pages 1-15 in Land use scenarios: environmental consequences of development. CRC Press, Boca Raton, Florida, USA.

Sheppard, S. R. J. 2006. Bridging the sustainability gap with landscape visualisation in community visioning hubs. Integrated Assessment 6(4):79-108.

Sheppard, S. R. 2012. Visualizing climate change: a guide to visual communication of climate change and developing local solutions. Routledge.

Sheppard, S. R. J., and M. Meitner. 2005. Using multi-criteria analysis and visualisation for sustainable forest management planning with stakeholder groups. Forest Ecology and Management 207:171-187. https://doi.org/10.1016/j.foreco.2004.10.032

Sheppard, S. R., A. Shaw, D. Flanders, and S. Burch. 2008. Can visualization save the world? Lessons for landscape architects from visualizing local climate change. Digital Design in Landscape Architecture 29-31.

Sheppard, S. R. J., A. Shaw, D. Flanders, S. Burch, A. Wiek, J. Carmichael, J. Robinson, and S. Cohen, S. 2011. Future visioning of local climate change: a framework for community engagement and planning with scenarios and visualization. Futures 43 (4):400-412. https://doi.org/10.1016/j.futures.2011.01.009

Singh, A. S., A. Zwickle, J. T. Bruskotter, and R. Wilson. 2017. The perceived psychological distance of climate change impacts and its influence on support for adaptation policy. Environmental Science \& Policy 73:93-99. https://doi.org/10.1016/j.envsci.2017.04.011

Smardon, R. C. 1984. When is the pig in the parlor? The interface of legal and aesthetic considerations. Environmental Review 8 (2):146-161. https://doi.org/10.2307/3984192

Swetnam, R. D., and J. Korenko. 2019. Can computer game landscapes target new audiences for landscape quality assessment? Applied Geography 113:102. https://doi.org/10.1016/ j.apgeog.2019.102102

Taylor, J. G., and T. C. Daniel. 1984. Prescribed fire: public education and perception. Journal of Forestry 82(6):361-365.

Timberlake, T. J., and C. A. Schultz. 2017. Policy, practice, and partnerships for climate change adaptation on US national forests. Climatic Change 144(2):257-269. https://doi.org/10.1007/ s10584-017-2031-z

Tress, B., and G. Tress. 2003. Scenario visualisation for participatory landscape planning - a study from Denmark. Landscape and Urban Planning 64(3):161- 178. https://doi. org/10.1016/S0169-2046(02)00219-0 
Tufte, E. R. 1990. Envisioning information. Graphics Press, Cheshire, Connecticut, USA.

Walker, B., C. S. Holling, S. R. Carpenter, and A. Kinzig. 2004. Resilience, adaptability and transformability in social-ecological systems. Ecology and Society 9(2)5. https://doi.org/10.5751/ ES-00650-090205

Weller, R. 2008. Planning by design landscape architectural scenarios for a rapidly growing city. Journal of Landscape Architecture 3(2):18-29. https://doi.org/10.1080/18626033.2008.9723401

Zube, E. H., D. G. Pitt, and G. W. Evans. 1983. A lifespan developmental study of landscape assessment. Journal of Environmental Psychology 3(2):115-128. https://doi.org/10.1016/ $\underline{\mathrm{S} 0272-4944(05) 80151-3}$ 


\section{APPENDIX 1.}

Survey content by site. The text version contains background and detailed strategy narratives for added context with each of the images, while the non-text version contains only the strategy title with each of the images. Scenarios are listed here in the order of passive/unmanaged, traditional restorative/utilitarian, and climatically adaptive strategies but appear randomized for participants in the actual survey.

Fig. A1.1 - Site 1: San Joaquin River at Temperance Flat

Background: The San Joaquin River Gorge Recreation Area, one of the last free flowing portions of the San Joaquin River that is not dammed, provides multiple recreational opportunities, including hiking and access to the Millerton Caves. T wo proposals have been made concerning this portion of the San Joaquin River, one is to build a new dam, and another is to designate eight miles as a Wild and Scenic River.

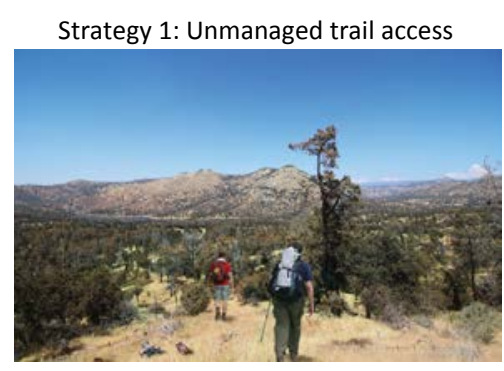

Strategy 1: Vulnerability to tree mortality and high severity fire are increased through years of drought and variable precipitation, and the ability of the ecosystem to retain and provision ground water and carbon is diminished. The social conditions are diminished when the scenery of an overly dense and dry woodland is coupled with the impacts of visitor overuse resulting from unmanaged recreational access. Rate the three images as " 1 " being most preferred and "3" being your least preferred.

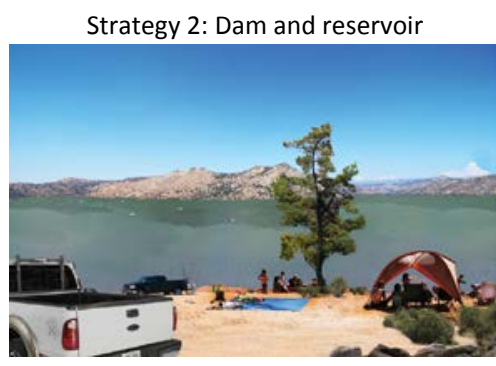

Strategy 2: The site is developed as part of the proposed Temperance Flat reservoir. The reservoir displaces the existing woodland ecosystem of the watershed and creates a new shoreline with variable height. Recreational access for the reservoir is managed with limits, but not much infrastructure is built for the high levels of vehicle use, which makes it difficult for new species to establish and newly adapted ecotones to form.

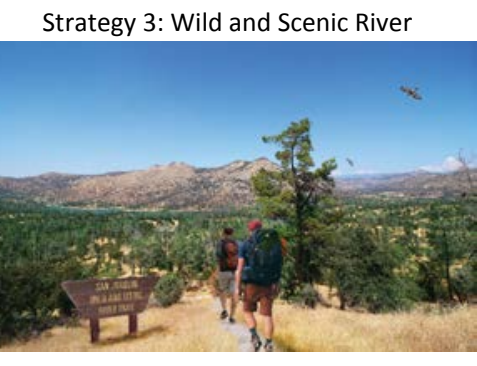

Strategy 3: Woodlands within the watershed are managed as green infrastructure by sequestering carbon and regulating hydrological processes, provisioning groundwater, and buffering downstream communities from extreme flood events. Recreational access is managed under Wild and Scenic River guidelines with only the necessary minimal infrastructure designed to adequately accommodate and reduce the impacts of non-motorized access for hiking, caving, and river recreation. 
Background: The Kern River is a water source for urban and agricultural use, stored in Lake Isabella, but it is also a source of tourism, linked to the local economy of the town of Kernville, in the way of camping, rafting and fishing. Climate change is predicted to cause irregularities and intensities between annual precipitation levels and snowmelt timing, thus affecting the river tourism industry that Kernville depends on.

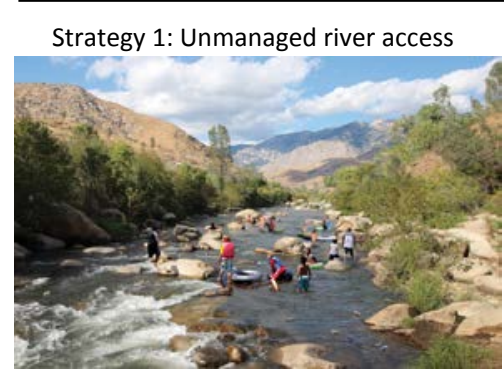

Strategy 1: A combination of low and variable precipitation years results in reduced river flow. Unmanaged impacts from high visitor use levels contribute to degraded near river habitat. The coupled impacts from continued low water levels and visitor overuse lead to a more vulnerable river ecosystem.

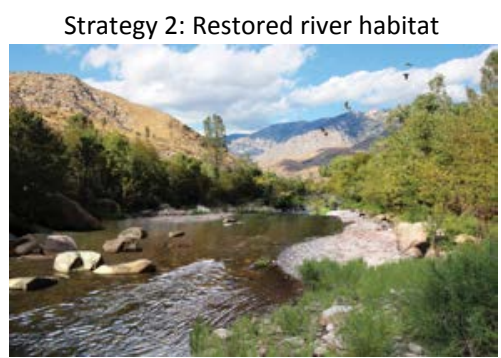

Strategy 2: The nearshore habitat of the river is restored from visitor overuse and the river is channelized to ensure a minimum water depth exists for instream species. In this case visitors are restricted from accessing the river in order to maintain restored conditions that help to buffer for climatic variability.

\section{Strategy 3: Channelization with rapids}

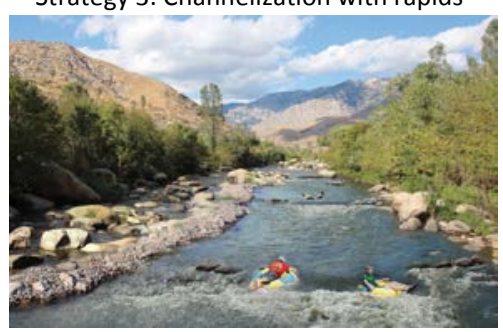

Strategy 3: This stretch of the river is managed for both habitat restoration and visitor use in variable precipitation years. River access is limited to permitted outfitters with select entry and exit points to help mitigate visitor impacts to nearshore habitat, and in river features such as rocks are engineered to create rapids for recreational use as well as instream habitat with low waterflow in mind.

Fig. A1.3 - Site 3: Lower Owens River

Background: The Owens River runs along the east side of the Sierra Nevada and historically had extremely low flows due to over extraction of water by the LADWP but has since been restored to a more natural river flow. In one portion of the river, a large Tule and cattail wetland is obstructing the flow of water, causing diminished water quality to downstream users, fish die offs, habitat loss for threatened species and a lower quality grazing habitat for cattle.

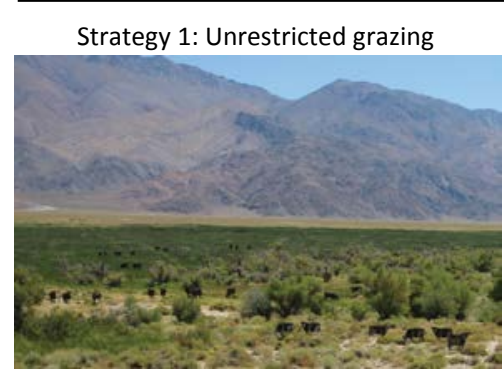

Strategy 1: In low precipitation years the river continues to flow but at a level below what is needed to maintain viable fish populations. That, in combination with the unmitigated impacts to water quality and over browsing from passive grazing, results in a river ecosystem that is more vulnerable to drought and increased heat.

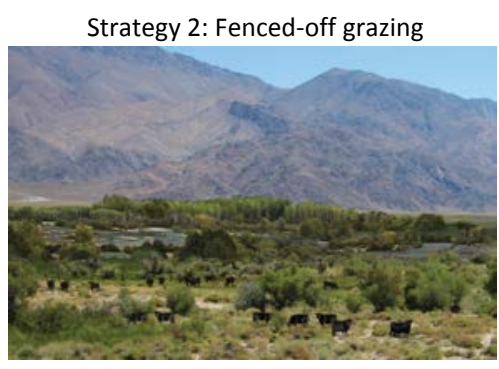

Strategy 2: Fencing off the river corridor from grazing and recreational access results in less impacts to the river ecosystem that would otherwise exist with unmanaged grazing and visitor overuse. This strategy would improve proximate fish habitat and water quality for downstream use.
Strategy 3: Fishing \& recreational access

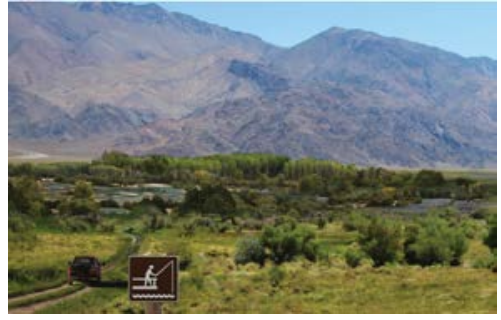

Strategy 3: In this scenario water levels are controlled year-round through upriver releases to achieve a compromise between near-historic hydrological regimes and that year's available water supply. Instream species and near river vegetation would be managed as an indicator of ecosystem health. Minimal visitor infrastructure would be added to limit the impacts associated with access for permitted 
Background: Meadows in the Sierra ecosystems provide carbon storage, groundwater storage, water filtration, and unique habitat for native trout species, but cattle grazing of Sierra meadows has had detrimental effects on meadows, as cattle tend to aggregate around water sources, trampling vegetation, eroding stream banks and compacting soil. The degradation of meadow streams from grazing, along with climate induced warming of stream waters and the introduction of non-native trout are affecting the ability for native trout species to survive in these iconic recreational fishing sites.

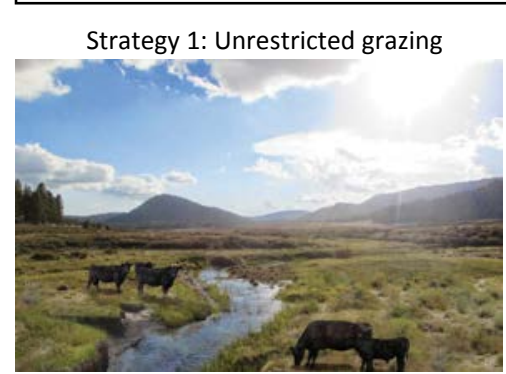

Strategy 1: With passive grazing there are no controls for over browsing and erosion. Although grazing leases are permitted in many wilderness areas, the use of an already vulnerable meadow system for seasonal fodder significantly deteriorates the physical character and cultural expectations associated with wild places.

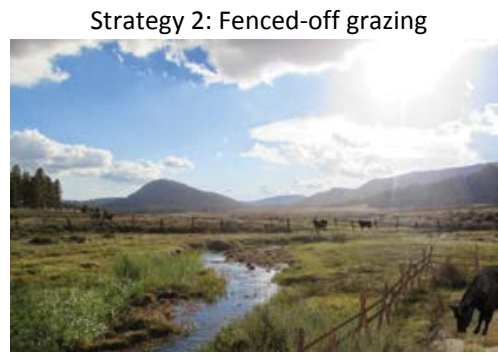

Strategy 2: Grazing is still permitted but restricted by fencing to the non-riparian areas of the meadow. This reduces erosion, which facilitates plant recovery and improves water quality in the stream corridor, which allows the meadow to partially recover. However, browsing is restricted to the outer portions of the meadow, which may increase the likelihood of forest succession, albeit gradually. In addition, the fence poses an aesthetic impact to wilderness character where signs of intervention are otherwise limited.
Strategy 3: Fishing and recreational access

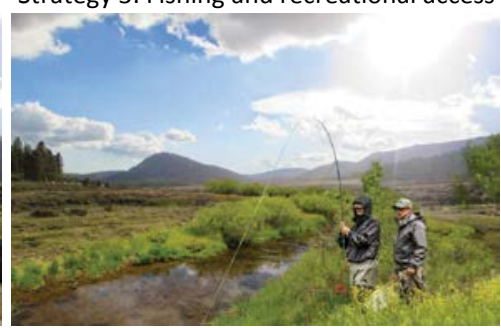

Strategy 3: Grazing is restricted from the meadow and surrounding forest. Water quality and near stream vegetation significantly increases. The stream becomes more channelized due to less erosion and the greater water content retained in the meadow allows the system to resist succession to forest. The trout population returns to a meadow with naturalized conditions, and with sufficient numbers recreational fishing is again seasonally permitted.

\section{Fig. A1.5 - Site 5: Big Meadows in Sequoia National Forest}

Background: A large portion of Sierra meadows have been degraded by overgrazing, drying, and lodgepole pine encroachment and thus have lost their ability to regulate seasonal water flow and filter out unwanted constituents. Many meadows are being restored to improve their hydrological function.

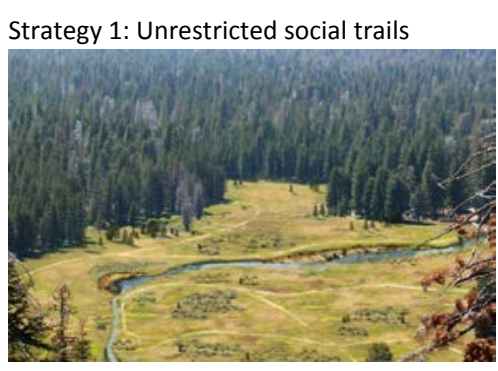

Strategy 1: Unmanaged recreational access to meadows can result in social trails that degrade and fragment the hydro-ecological interface. The erosion caused by these emergent trails may also reduce water storage capacity of the system, making it more vulnerable to forest succession. The physical marks of unchecked recreational use may also impact the scenic conditions that visitors expect and rely upon.

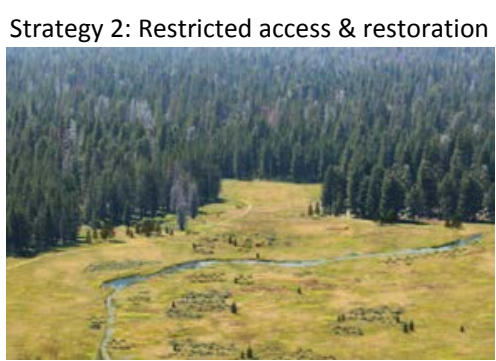

Strategy 2: Limiting visitor use to a narrow trail corridor along the edge of the meadow and forest reduces the number of trails in the meadow to help restore the soil and vegetation of this ecosystem. However, this strategy focuses on restoration back to a known, historic baseline rather than anticipation of future climate change, such as increased heat and drought conditions that may lead to forest succession.
Strategy 3: Prevent tree encroachment

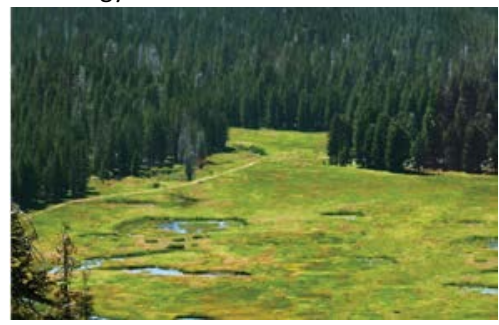

Strategy 3: While drought and heat will be common determinants of future forest and meadow conditions, there are strategies to adaptively resist successionary change. The 'plug and pond' retention method is one approach that increases meadow water storage and thereby staves off tree encroachment due to the difficulty lodgepole pines have in tolerating high soil moisture levels. 
Background: Fire is one of the driving disturbances in forests that maintains ecological balance but because of past fire suppression, many Sierra forests have grown overcrowded and are at a higher risk for severe wildfires. Sequoia National Park was one of the first parks to employ prescribed burning as a management strategy to restore forest health and minimize the risk of severe wildfires.

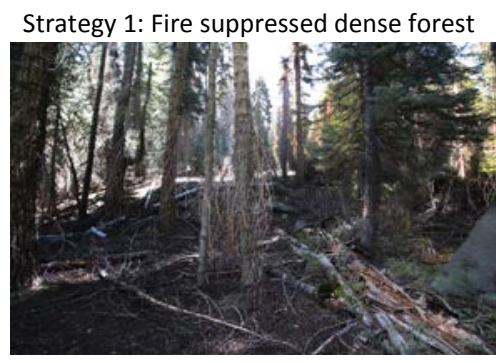

Strategy 1: Overly dense tree stands, and canopy cover impact the forest ecosystem by limiting available ground cover and light for flora, and access to habitat for many fauna. These conditions make the forest vulnerable to high severity fire and difficult to access for recreational use.
Strategy 2: Mechanically thinned forest

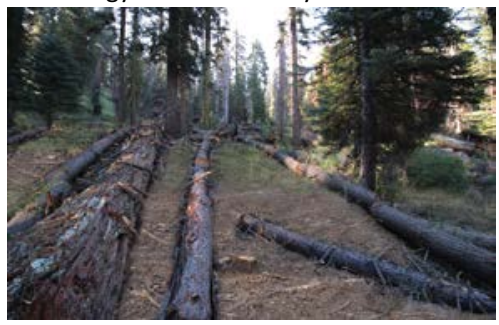

Strategy 2: Forest thinning can open canopies to provide more available light, which along with clearing of detritus on the ground can encourage more native plant growth in the understory. This improves habitat conditions for many species and reduces susceptibility to high severity fire events.

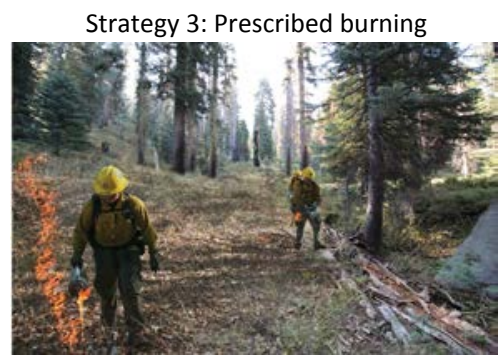

Strategy 3: Low level prescribed fire is an adaptive management method that increases forest resilience amid changing climatic conditions. Prescribed burning can maintain thinned forests, native groundcover, and increase groundwater retention. Forests managed with fire are typically more resistant to collapse like with forests that are unmanaged, overly dense, and contain less drought-tolerant endemic species.

Fig. A1.7 - Site 7: Railroad Fire near Sugar Pine

Background: The Railroad Fire of 2017 burned 12,000 acres of forest land near Sugar Pine. The fire burned intensely in areas that had already experienced high levels of tree mortality as well as in areas that had previously been treated by prescribed burning and mechanical thinning. Post-fire forests are managed for multiple outcomes including, prevention of erosion and its effects on watersheds, harvesting viable timber products, minimizing the risk of future insect outbreaks, minimizing the severity of subsequent fires, and promoting ecosystem regeneration.

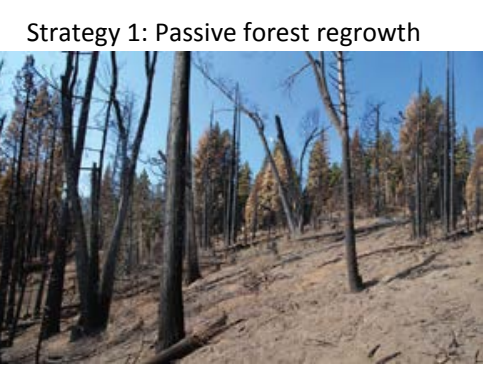

Strategy 1: Post-fire ecosystems and the soil that underlies them are sensitive environments. The state of the forest that succeeds these scarred landscapes is in large part determined by the conditions of the system at this point. If nothing is done to course correct, then the forest is likely to again fill in with many young trees not necessarily adapted to future extremes resulting in overly dense stands highly vulnerable to further high severity fires. Importantly however, if soils are left intact without soil compaction then the understory vegetation and conifer growth can recover.

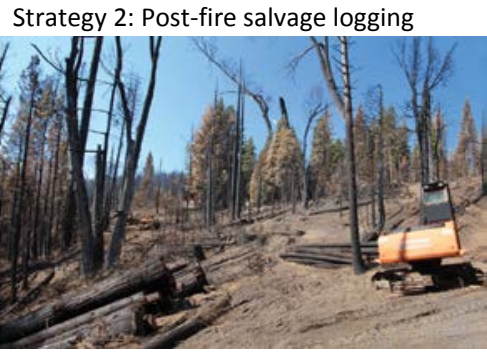

Strategy 2: Post-fire salvage logging in places damaged by wildfire and other natural disturbance allows remaining timber to be utilized, however the use of heavy machinery, as is common with this practice, results in serious impact to soil compaction which can result in delayed understory and conifer growth. While this strategy may be beneficial for the local economy in the short term, delayed succession may ultimately lead to a more vulnerable forest system, subject to greater erosion and without the necessary biomass and tree age class diversity needed to regenerate the ecosystem.
Strategy 3: Climate-adapted regrowth

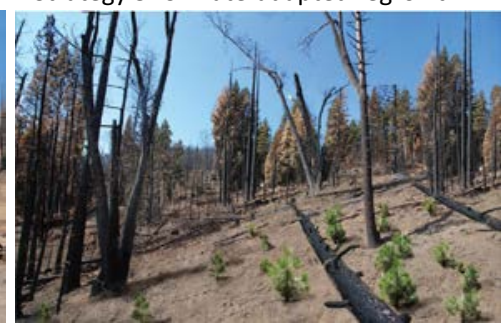

Strategy 3: Facilitated regeneration is practiced as a low-impact method to manually plant conifer seedlings that originated from a population more genetically adapted to the future temperature and precipitation conditions at this site. By avoiding compaction caused by heavy machinery and plating seedlings, the soil can retain more precipitation as groundwater, and there is less potential for post-fire run-off. This method, at once assisted migration and adaptive forest succession management, may help to reduce vulnerability to high severity fires so long as occasional lowlevel prescribed burns are utilized to maintain conditions going forward. 
Fig. A1.8 - Site 8: Case Mountain Giant Sequoia Complex

Background: Climate change prediction models show that temperatures in the Southern Sierra will increase and that precipitation patterns will change inevitably affecting the narrow climatic envelope of the giant sequoia range. The groves of the Case Mountain Complex are the only giant sequoias managed by the BLM. Currently, these groves are full of dense mixed conifer growth, ladder fuel, and a heavy forest floor fuel load, all conditions that could contribute to the spread of a severe fire in the future.

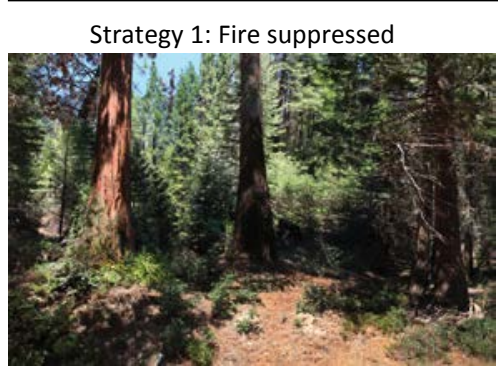

Strategy 1: Giant sequoias rely on heat from fire to open seeds in their cones. Despite this, many sequoia groves lie within forests that are otherwise managed for fire suppression. This not only limits species reproduction but also leads to overcrowding of understory vegetation and competing conifers that in turn make the groves more vulnerable to high severity fire beyond what the species has adapted to. The dense tree stands in this scenario provide limited opportunities for visitor use access, which stands in contrast to low level of groundcover of naturalized groves.

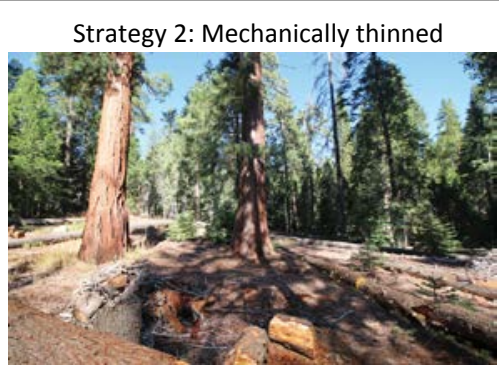

Strategy 2: One method to restore sequoia groves back to a more naturalized composition is to remove competing conifers and masticate the remaining ground cover. This mechanical thinning is a temporary solution that doesn't consider future climatic variability or maintain low level prescribed burns. Furthermore, soil compaction from mechanical thinning can poses a risk to the shallow root structure of the sequoias and this method may impact scenic expectations of visitors.
Strategy 3: Prescribed burning

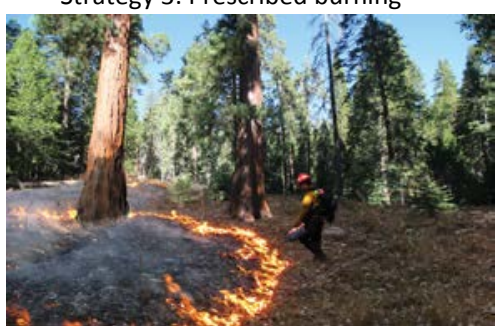

Strategy 3: The use of low-level prescribed burns in giant sequoia groves is an adaptive management strategy that allows for soil regeneration, maintenance of low groundcover, and sequoia seedlings to activate under heat. Although due to historic suppression some thinning may be necessary before low level burns can be employed, further semi-annual prescriptions can keep the groves in a functionally resilient state that's more accessible for limited visitor use.

\section{Fig. A1.9 - Site 9: Dinkey Collaborative Forest Program}

Background: The Dinkey Landscape Restoration Collaborative is a forest restoration program in the community near Dinkey Creek and was formed in $\mathbf{2 0 1 0}$ to be an ecological restoration management group based on science with the main goals of improving the health of the forest, minimizing chances of severe wildfire and benefiting the local economy. The area that the Dinkey Collaborative oversees, has experienced high tree mortality, and they have begun working to thin and remove the dead trees.

Strategy 1: Fire suppressed forest

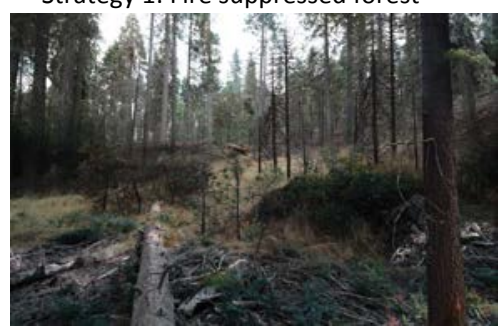

Strategy 1: The continued paradigm of fire suppression results in denser tree stands, which contain many smaller trees as opposed to a thinner stand of larger trees. In some cases, the biomass of these dense stands is as much as ten times that of pre-suppression forest structure. These forests are more vulnerable to high severity fires, which pose hazards to structures and diminish air quality in nearby communities.
Strategy 2: Mechanically thinned

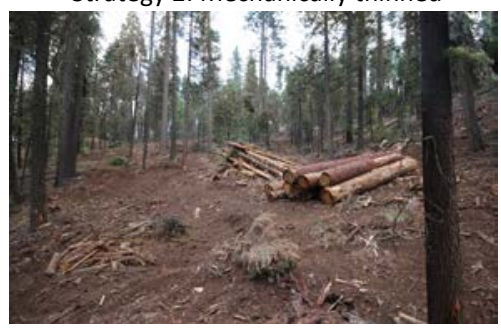

Strategy 2: Mechanical thinning, also known as selective logging, can be used to space out the forest to a near presuppression density. Mastication techniques that clear the forest floor of biomass can be applied in parallel. These methods increase the resilience of the forest, however further thinning efforts will need to be undertaken with continued tree mortality and understory growth. Thinning can provide a small economic return to the community but may not be politically feasible at the scale needed to address the issue.
Strategy 3: Climate-adapted regrowth

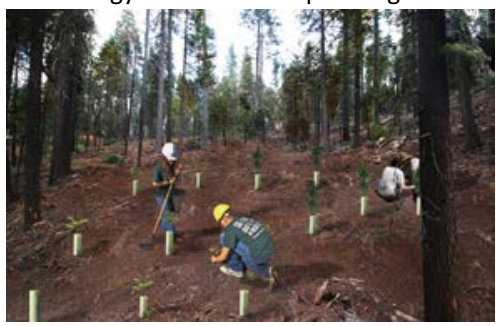

Strategy 3: Assisted migration of mixed conifer and oak forests into a new climatic envelope can help to buffer the system from further collapse associated with largescale tree mortality of pines. Tree mortality from native pine bark beetle is exacerbated by the stress of hotter and drier climate coupled along with dense tree stands. Forest floors can be manually thinned and species more adapted to future conditions can be planted amid natural canopy openings, which can reduce the vulnerability of the forest to high severity fire and limit scenic impacts of pervasive die-off. 
Fig. A1.10 - Site 10: Table Mountain Preserve

Background: The Sierra foothills are a biologically diverse region of mixed oak woodlands where ranching is a historically important land use. Large ranches are significantly more beneficial to ecosystems, relative to the exurban development seen throughout the wildlandurban interface. While grazing is a culturally valued land use for some, so too are both access to recreational amenities and the ecological preservation of endemic species for others.

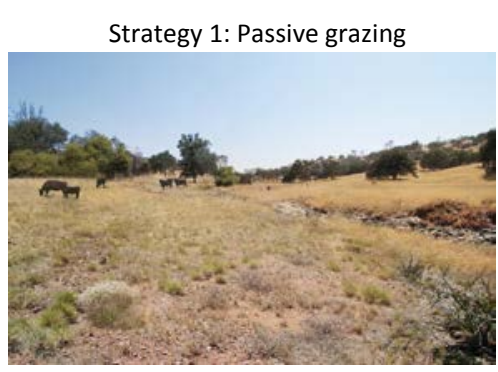

Strategy 1: Foothill ecosystems are subject to the vulnerabilities of a shifting climatic envelope and historic land uses, a double exposure that's magnified with increasingly common lower precipitation and higher temperatures years. Passive grazing is impactful if not managed, but this physical and scenic degradation is magnified when already stressed ecosystem conditions exist from drought and heat.

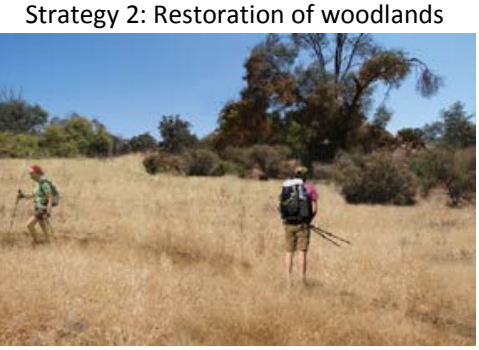

Strategy 2: Grazing can be curtailed or restricted during years of variable climatic conditions. The absence of grazing may allow vegetation to remain intact and standing, however a changing climate means that the range has shifted for plants that once flourished in this narrow temperature and precipitation band along the Sierra. Despite these changing conditions, foothill open spaces will remain open for recreational use given their proximity to the Valley.

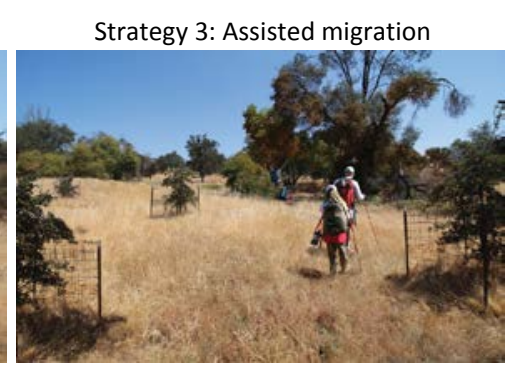

Strategy 3: An adaptive strategy for managing ecosystems with shifting climatic envelopes is to assist in the migration of species, which are themselves being pushed out of a narrow temperature and precipitation band, to a climatic-ecological niche that these species are now best suited to occupy. In this scenario continued recreational access and additional community support for assisted migration projects leads to sustained visitor use.

\section{Fig. A1.11 - Site 11: Highway 190 near Camp Nelson}

Background: Sierra roadways will be impacted by more variable and extreme weather, and the resulting impacts of wildfire, erosion, flooding, landslides, and pavement deterioration. When wildfires burn understory vegetation, erosion control is lost, and methods need to be used in order to manage for potential mudslides, rockslides and flooding.

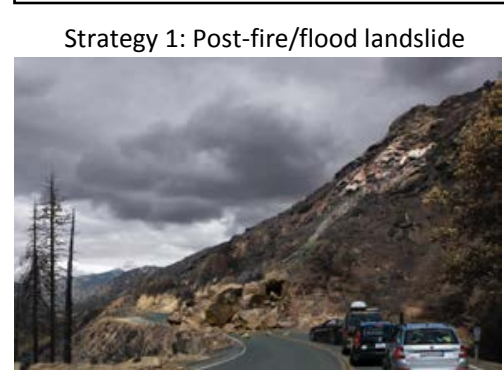

Strategy 1: High severity fires can burn both the groundcover and overstory vegetation. In so doing the surface water absorption and stabilizing characteristics of soil and roots are compromised. Landscapes with steep slopes are made more vulnerable when fire disturbance is followed by a high-volume precipitation event, which can lead to rock, mud, and landslides that can impact roads.

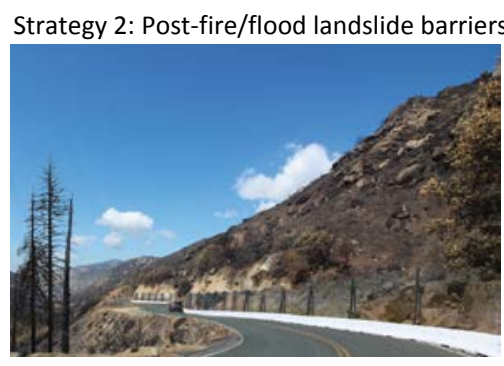

Strategy 2: A double exposure happens when fires and floods impact nearby infrastructure such as roads that people rely upon for commerce, tourism, and life. Traditionally these hazards to roadways are limited by barriers erected to restrain otherwise natural processes from impacts to roadways. However, larger magnitude events associated with climate change mean that this command and control solution has its limits.
Strategy 3: Post-fire/flood reseeding

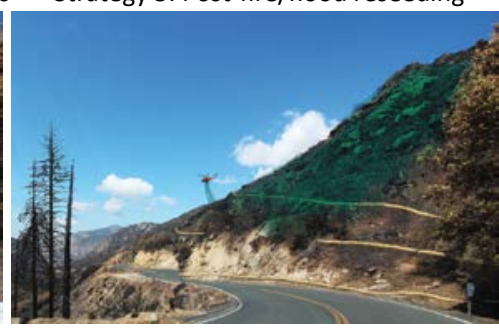

Strategy 3: One strategy that can help to prevent or mitigate the impacts of slides is the reseeding of hillsides after high severity fire events. The use of native plants with drought resistant root structures in combination with erosion control methods like the use of straw socks can help to lessen the impacts of post-fire landslides and increase the likelihood that roadways won't be damaged. 
Background: With the onset of warmer winters and increased drought conditions in California and the Sierra, snowpack will become more variable and as some result recreational skiing opportunities will be less certain. Ski resorts either must adapt by adjusting their recreational activities or by making snow with machines.

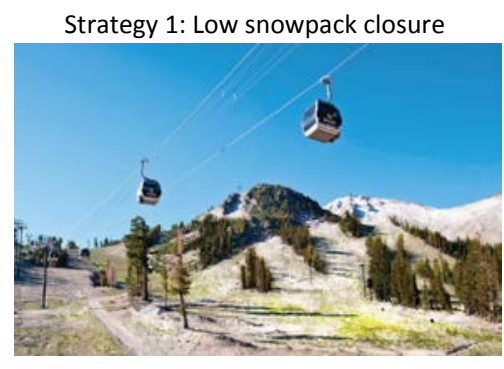

Strategy 1: Low or variable snowpack will result in ski area closures. These years of drought and increased temperatures may result in expanded tree mortality to higher elevations, which in conjunction with unmanaged recreational access would contribute to ecologically vulnerable conditions.

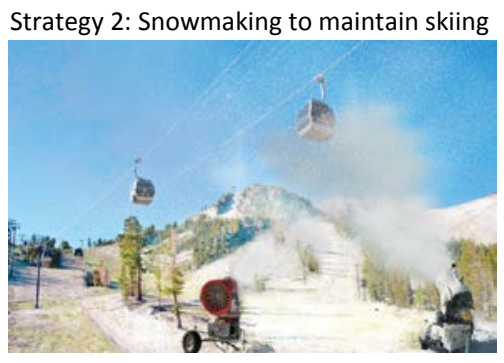

Strategy 2: Snowmaking can be employed to restore more certain conditions for expected winter recreation. This interventionist approach would rely on greater water and power generating ability from nearby source watersheds that are already in drought, thus leading to greater reliance on already vulnerable supplies.

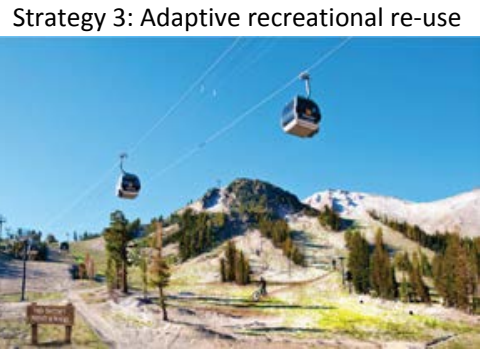

Strategy 3: Shifting recreational use to incorporate typically non-winter sports, such as biking, as a year-round option is a resilient alternative that doesn't rely on limited water and energy sources associated with drought. Managed trail access can limit ecological impacts for already vulnerable species to a narrow trail corridor. 